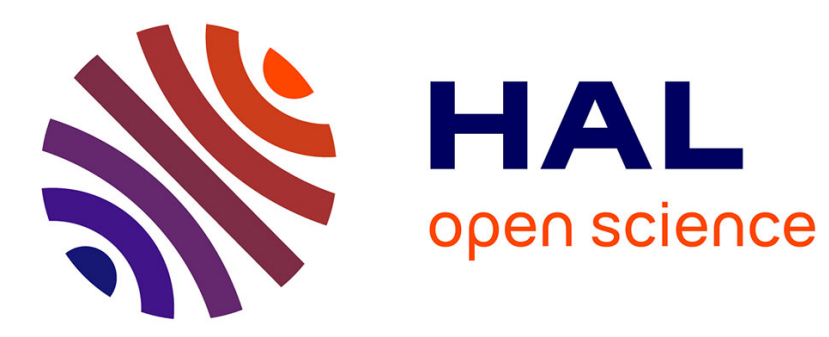

\title{
A Flexibility-based Approach for the Design and Management of Floating Offshore Wind Farms
}

Samuel Torres-Rincón, Emilio Bastidas-Arteaga, Mauricio Sánchez-Silva

\section{To cite this version:}

Samuel Torres-Rincón, Emilio Bastidas-Arteaga, Mauricio Sánchez-Silva. A Flexibility-based Approach for the Design and Management of Floating Offshore Wind Farms. Renewable Energy, 2021, 10.1016/j.renene.2021.04.121 . hal-03227109

\section{HAL Id: hal-03227109 \\ https://hal.science/hal-03227109}

Submitted on 16 May 2021

HAL is a multi-disciplinary open access archive for the deposit and dissemination of scientific research documents, whether they are published or not. The documents may come from teaching and research institutions in France or abroad, or from public or private research centers.
L'archive ouverte pluridisciplinaire HAL, est destinée au dépôt et à la diffusion de documents scientifiques de niveau recherche, publiés ou non, émanant des établissements d'enseignement et de recherche français ou étrangers, des laboratoires publics ou privés. 


\title{
A Flexibility-based Approach for the Design and Management of Floating Offshore Wind Farms
}

\author{
Samuel Torres-Rincón ${ }^{\mathrm{a}, \mathrm{b}, *}$, Emilio Bastidas-Arteaga $^{\mathrm{b}}$, Mauricio Sánchez-Silva $^{\mathrm{a}}$ \\ ${ }^{a}$ Civil and Environmental Engineering Department, Universidad de los Andes, Bogotá, Colombia \\ ${ }^{b}$ University of Nantes, Institute for Research in Civil and Mechanical Engineering, CNRS UMR 6183, Nantes, \\ France
}

\begin{abstract}
Floating offshore wind farms have become a gateway to reach locations that are technically and economically infeasible to exploit using fixed platforms. However, the high capital investments and the uncertainty associated with the reliability, capacity factor, technology evolution, electricity demand, and regulatory frameworks negatively affect the cost of energy of this approach. Alternative strategies, such as designing for flexibility, have been shown to increase the value of engineering systems subject to highly uncertain environments. In this article, an analysis based on life-cycle costs and MonteCarlo simulation is used to determine if floating wind farms with flexible installed capacity result in lower costs of energy than traditionally designed wind farms. Flexibility is introduced using an adaptable platform strategy and an over-dimensioned platform strategy. The results show that the adaptable platform strategy has the potential to reduce the cost of energy up to $18 \%$ by increasing the energy generation and the lifetime of some components of the wind farm. Nonetheless, the benefits of flexibility depend on new legislation that allows for lifetime extensions and proper flexibility management policies that utilize the potential built into the systems.
\end{abstract}

Keywords: Floating offshore wind generation, Flexibility, Adaptability, Life-cycle analysis, Repowering

\section{Introduction}

Offshore locations have become a viable option to expand wind energy generation $[1,2]$ in the last decade. By 2020, the European Wind Energy Association expects to have between 19 and 27 GW installed [3]. However, the costs of building, maintaining, and operating offshore farms are higher than their onshore and close-to-shore counterparts $[4,1]$ due to the trend of increasing turbine sizes [5] and moving to deeper waters $[6,7,8,9]$ in locations far from shore and difficult access. To facilitate the exploitation of these remote locations, floating platform concepts have been proposed following the example of the oil and gas industry [9]. The main appeal of this concept is that it unlocks locations with water depths greater than $50 \mathrm{~m}$, where bottom-fixed concepts are either technically infeasible or economically unfeasible [1]. However, the capital costs of floating projects can be as large as twice the cost for shallow waters [10]. These additional costs are partially explained by the extra length

\footnotetext{
* Corresponding author

Email address: sf.torres405@uniandes.edu.co (Samuel Torres-Rincón ) 
of mooring and export cables required [1], but also by the larger turbines deployed [2] and massive

floating platforms. Furthermore, the difficulty to access remote locations increases both operation and maintenance costs due to the need for high-reliability [11].

The expected tendency is that larger and more expensive turbines will be available for farms located further from shore as the industry keeps developing [12]. For instance, a rapid increment in rotor diameter and hub height is reported in [5]. These measures are justified for reports such as [13], where it is stated that increasing the turbine power rating is the technological innovation that has the highest impact on reducing the energy cost. Other authors [14] report that doubling installed capacity can reduce the LCOE between 9 and $17 \%$.

Going far from shore poses the additional challenges of dealing with extreme meteorological conditions that affect the reliability of the grid, increases maintenance costs, and increases turbines' downtime [7]. Möller et al [6] also identified larger uncertainties for far from shore scenarios, which may result in costs underestimation. Further sources of uncertainty related to external social phenomena such as market dynamics, demographic changes, political environment, the evolution of regulatory frameworks, and the development of new technologies pose additional challenges to the management and economic viability of offshore projects. These elements portrait a challenging landscape for offshore floating wind generation: large capital investments and a highly uncertain environment.

These conditions establish the need for innovations and alternative design and management philosophies. The cost reduction effect of increasing installed capacity points towards the implementation of re-powering and lifetime extension strategies. Large costs are not the only challenge faced by floating offshore generation; highly uncertain environments also affect the system output, not only from a technical perspective but also from its perceived competitiveness. If floating offshore generation is to become a viable source of renewable energy, it needs the tools to deal with a complex uncertain environment, which requires going beyond re-powering strategies.

Different authors $[15,16,17,18,19]$ have identified flexibility and adaptability as key properties to have in engineering systems in the face of uncertainty. These authors associate flexibility with a reduction in the negative impact of uncertainty and even an increased ability to better exploit new conditions. In the context of engineering systems, flexibility is usually defined as the ability of a system to be easily modified [20, 21, 22, 23, 24]. The option for future changes is introduced during the design stage and it is usually coupled with a management policy that suggests when an adaptation should be executed. In the case of wind turbines, flexibility already exists in different components in the nacelle that allow to increase the turbine efficiency and control the operating conditions. However, in this paper we consider flexibility as the option to increase the power rating of the turbines by installing adaptable floating platforms that enable fast replacements.

Although flexibility can be used to achieve re-powering, the concept goes beyond by including specific design measures to enable fast turbine replacement. Furthermore, the concept does not limit its applicability to specific time instants but takes proactive measures in the form of management policies to consider a wide range of external conditions that could motivate an adaptation. However, flexibility does not address problems encountered in re-powering approaches associated with the 
financial closure and regulatory compliance of the project.

Developing floating offshore wind farms with flexible capacity could potentially increase the service life and reduce the LCOE. By allowing a fast deployment of larger generators, the wind farm could take advantage of new technologies to increase the installed capacity with reduced production and installation costs. A flexible design and management strategy could improve the competitiveness of operating offshore farms under variable external conditions. For these reasons, this work presents a parametric analysis to evaluate if flexibility is a valuable property for floating offshore wind farms from a life-cycle cost perspective. The results show not only that flexibility can be a desirable property, but also identify the flexibility configurations and management policies that produce the lowest LCOE.

This article is organized as follows: section 2 provides a literature review on the concept of flexibility in the context of engineering systems, section 3 presents the life-cycle cost model used to determine the costs for the baseline and flexible strategies, section 3.3 explains the simulation methodology followed to calculate the LCOE for all cases, and section 4 exemplifies the cost model and simulation methodology in a theoretical farm under multiple scenarios. The results obtained in this section are used to draw conclusions about the impact of flexibility in the cost of energy of floating offshore wind farms.

\section{Literature review: flexibility in engineering systems}

The concept of flexibility in engineering systems is not considered to be "academically mature" [21] because an exact and commonly agreed definition is yet to be proposed. In this work, flexibility will be understood as defined in [25, 22, 24]: Flexibility is the ability of a system to easily adapt any of its components. The measurement of the effort is generally given in terms of the resources needed to perform the change. It is assumed that an initial investment is required to introduce the option. This additional expenses may come from lengthier design processes and additional materials. It is expected that the size of the initial investments will limit the scope of the adaptations that can be performed through flexibility.

This description of flexibility can be translated into a numerical representation, which can be useful to compare different flexible designs for the same system. This study uses the flexibility vector [24] described by Equation 1:

$$
\mathbf{f}_{i}(t)=\left[\frac{c_{n f, i}-c_{f, i}}{c_{f, i}}, \frac{x_{\max , i}(t)-x_{i}(0)}{x_{i}(0)}\right]
$$

This vector describes the flexibility for the design/operational parameter $i$ using two components: the first component measures the resources required to perform an adaptation as the ratio between the unitary cost of modifying $i$ without flexibility $c_{n f, i}$ (without being specifically designed to be adapted); and the unitary cost of performing an adaptation with flexibility $c_{f, i}$. The second component measures the size of the adaptation space as the ratio between the maximum value that $i$ can take and its initial value $x_{\max , i} / x_{i}(0)$. Following this definition, a system's element $i$ can increase its flexibility reducing the adaptation costs or by increasing the adaptation space. The flexibility vector in Equation 1 is 
defined for a single design or operation parameter of the system. Depending on the system, multiple flexibility vectors may be needed to describe all adaptation capabilities.

\subsection{Flexibility management policies}

Designing an engineering system to be flexible is not enough to obtain the reported advantages. The timing and magnitude of the adaptations need to be properly devised to ensure that the system response is optimal $[20,26,25,27,23,24]$. These decisions depend both on technical constraints on the system's performance and specific demands dictated by stakeholders' preferences, regulatory frameworks, and user requirements. These sets of preferences can be modeled using policies.

Policies are functions that map a set of system states to decisions [27, 28]. The family and specific parameters of the function allow encapsulating the set of preferences that control the adaptation process. While in some cases the adaptation policies take complex forms to consider risk preferences, for many applications a deterministic policy of the form of "if-then" conditionals that trigger an adaptation process [29] is enough to model a wide range of real-life conditions.

The use of policies allows to model the process of managing flexibility as a sequential decision process (SDP). The generic SDP model requires an environment and an agent that observes the state $s(t)$ of the environment at time $t$ and selects an action $a(t)$ based on the policy $\pi$. At the next time step, a reward $r(t)$ is generated by the environment and received by the agent, while a new state $s(t+1)$ is reached according to a probabilist model. This model combines random elements with the sequence of previous states $s(1: t)$ and actions $a(1: t)$ [30]. Then, the agent observes the new state and selects a new action $a(t+1)$ according to $\pi$.

In the case of flexible system management and design, the SDP is applied as follows: First, define the system's initial design properties $x(0)$ and $x_{\max }$ (flexibility range of design/operation parameter $x(t))$. Second, define the policy $\pi$ to guide the adaptation management decisions. Third, during the operation stage, the conditions defined by the policy are monitored to perform an adaptation if needed. This results in a sequence of time instants $\tau_{1}, \tau_{2}, \ldots$, and adaptation sizes $y_{\tau_{1}}, y_{\tau_{2}}, \ldots$ for all future adaptations. Figure 1 presents a diagram that synthesizes this design and management process.

\subsection{Flexibility in offshore floating wind turbines}

The concept of flexibility can be applied in different ways to floating offshore wind turbines. In this study two strategies are considered: i) over-dimensioned floating platforms that allow fast installation of new, larger turbines (Strategy A), and ii) floating platforms that are specifically designed to be adapted (expanded) when larger turbines are required and available (Strategy B) (see Figure 2).

While both strategies accomplish the same objective of allowing fast replacement of the wind turbines, Strategy B has higher design costs due to research and development activities required to design adaptable floating platforms. In contrast, production costs are higher for the larger platform of Strategy A due to its larger size. In both cases, however, the mooring and transmission lines are over-designed to restrict the adaptations to the platforms only. 


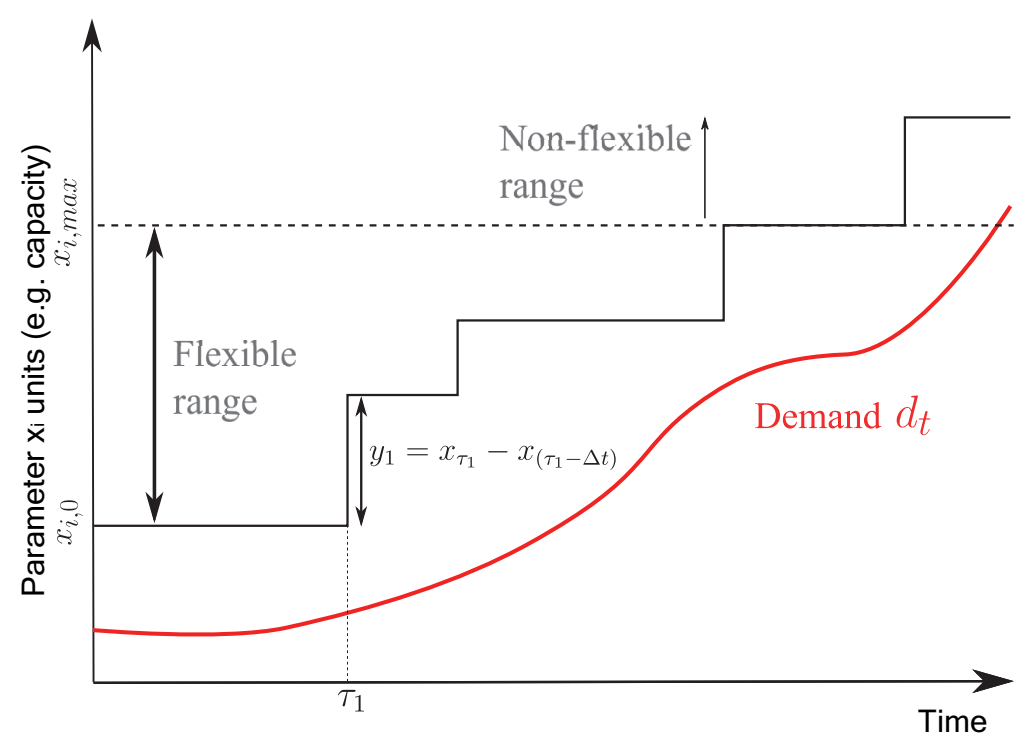

Figure 1: Description of the main elements for flexible designs

When an adaptation is performed, there are additional costs for Strategy B due to the necessary modifications to the platform. The platform from Strategy A has the advantage of allowing an immediate replacement of the turbine. In summary, the difference between strategies is the trade-off between initial and future costs. It is important to remark that the details of the design of the adaptable platform from Strategy B are beyond the scope of this study.

A key element to consider is the type of floating platform. There are three design concepts that commonly appear in the literature: i) semi-submersible platforms (SSPs), ii) spar buoys (SBs), and iii) tension-leg platforms (TLPs). Each platform type has different draft requirements that affect the installation process. While SSPs can be towed from port to the farm site, assembling the turbines with the SBs or TLPs and towing them from port is usually not an option due to the draft requirements for these platforms. The assembly is usually done in deeper waters using floating cranes before the joint turbine and platform can be towed to the site. Furthermore, the SSPs offer a shape more suitable for adaptable modular designs. According to [31, 32, 33], SSPs exhibit the lowest LCOE for a wide range of farm configurations. Assembly can be completed using only a port crane, which is considerably less expensive than using a floating crane. For these reasons, only SSPs are considered in this study.
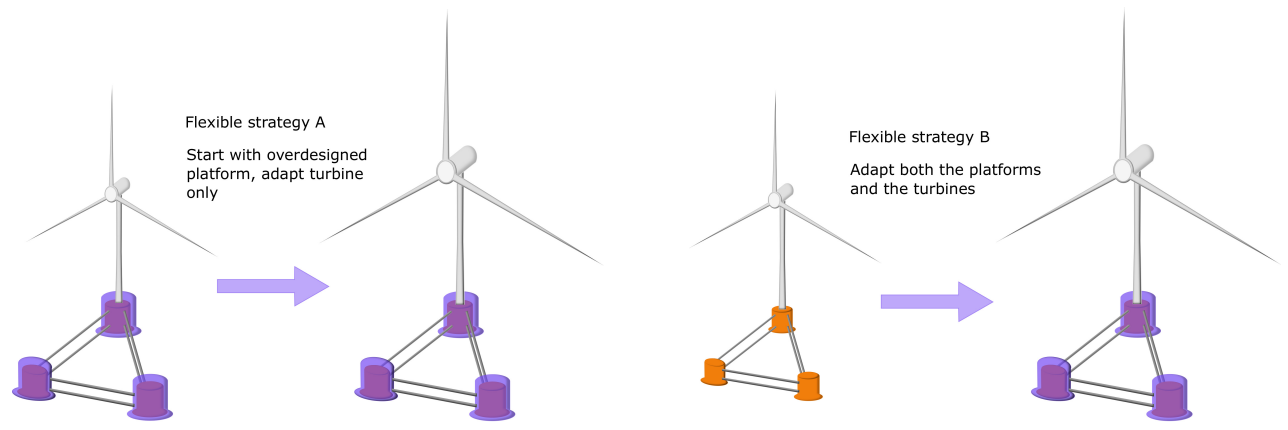

Figure 2: Flexible strategies for floating platform expansions 


\section{Life-cycle cost model}

The evaluation of the economic performance for the flexible strategies is conducted by estimating the Life-cycle Cost of Energy (LCOE) and comparing it with a baseline case with no flexibility. The LCOE is a measure widely used to compare energy generation alternatives by providing an estimation of the average cost of the energy generated.

Estimating these costs for a floating offshore farm is challenging due to the absence of commercial operating farms and the complexity of the systems [2]. The models proposed in [34, 33, 10] provide the best guides available. According to these models, the life-cycle costs of offshore wind farms can be associated with the following stages: i) planning, development, and design; ii) production and installation; iii) operation; and iv) decommissioning.

The planning, development, and design stage costs $P D D$ represent the cost of activities that must be completed before the construction phase such as surveys, development of design concepts, arrangement of legal requirements, and other activities related with project management. These costs are sometimes reported as a unitary price per unit of installed capacity.

The production and material costs, $P M$, are defined for each component: turbines, floating platforms, mooring and anchoring, and electrical systems. Turbines and platforms costs can be estimated from unitary prices and the capacity of the farm; mooring, anchoring and electrical systems' costs are estimated from a price per unit of length.

Installation costs $I$ depend mainly on farm component, distance from port, and installation procedure. In particular, the installation procedure determines the fleet composition which is a key element in the estimation of $I$. The next section summarizes the analytical expressions used to estimate these costs.

The operation and maintenance costs, $O M$, include transmission charges and maintenance activities. The transmission charges are usually represented as a constant amount paid to the government per MWh produced. Maintenance activities can be classified as preventive and corrective. Preventive maintenance costs are represented as a constant yearly cost, while corrective costs depend on the failure rate of individual components [11]. Various authors [8, 35, 12] have found empirical models to calculate these costs as a function of the installed capacity and the distance to shore.

In the case of flexible farms, the operation stage must include the adaptation costs $A$. For the flexibility strategies discussed in section 2.2 these costs vary as follows: For Strategy A, $A$ are the costs of acquiring and installing the new turbines. For Strategy B, $A$ includes both acquiring and installing new turbines and expanding the platforms. The estimation of these costs is detailed in section 3.2.4.

The costs of decommissioning $D$ include the labor costs, transportation costs, and processing costs [36]. These costs can be partially offset by recycling most of the raw materials. Empirical models in the literature [10] have estimated decommissioning costs as a percentage of installation costs depending on the farm component (turbines, cables, etc.).

Once these costs have been determined, the present value is calculated as: 


$$
P V_{C}=P P D+P M+I+\sum_{t=1}^{T} \frac{O M(t)+A(t)}{(1+r)^{t}}+\frac{D}{(1+r)^{T}}
$$

where $T$ is the planning horizon and $r$ is the discount rate.

\subsection{LCOE estimation}

To complete the estimation of the LCOE it is necessary to provide a single value to represent the energy generated. The total discounted generated energy $P V_{E}$ can be calculated using Equation 3.

$$
P V_{E}=\sum_{t=1}^{T} \frac{E(t)}{(1+r)^{t}}
$$

where $E(t)$ is the energy generated in time step $t$ in $M W h$.

The LCOE is then calculated as the ratio between $P V_{C}$ (Equation 2) and $P V_{E}$ :

$$
L C O E=\frac{P V_{C}}{P V_{E}}
$$

\subsection{Installation and adaptation costs definition}

As discussed at the start of section 3, installation costs $I$ and adaptation costs $A$ depend on farm location, turbine assembly strategy, and transport fleet composition. The estimation of these costs is done using analytical expressions to model the specific conditions. The following sections present the equations adapted from the models published in $[2,33,10]$.

Due to the large number of parameters, the following naming convention is adopted: $\operatorname{var}_{a, b}$, where var can be any variable from Table 1 , and $a, b$ can be physical elements from Table 2 or activities from Table 3. Subscript $a$ represent the direct element or activity measured by $v a r$ and $b$ is a complement. For instance, $n_{w t, b}$ represents the number of turbines transported per barge, while $n_{b, w t}$ represents the number of barges used to transport turbines.

Table 1: Variables' abbreviations

\begin{tabular}{cccccc}
\hline Symbol & Name & Unit & Symbol & Name & Unit \\
\hline$I$ & Installation cost & $€$ & $P M$ & Production and materials cost & $€$ \\
$P D D$ & Planning, development and design costs & $€$ & $O M$ & Operation and maintenance cost & $€$ \\
$A$ & Adaptation cost & $€$ & $D$ & Decommissioning cost & Unitary cost \\
$t$ & Time & hour & $c$ & Surface & Width \\
$d$ & Distance & $m$ & $s$ & Number of elements \\
$l$ & Length & $m$ & $w$ & Rate of installation \\
$k$ & Speed & $\mathrm{m} / \mathrm{s}$ & $n$ & & $\mathrm{~m}$ \\
\hline
\end{tabular}


Table 2: Elements abbreviations

\begin{tabular}{cccc}
\hline Symbol & Name & Symbol & Name \\
\hline$w t$ & Wind turbine & $f p$ & Floating platform \\
$t u g$ & Tug & $b$ & Barge \\
$p c$ & Port crane & $f c$ & Floating crane \\
$a$ & Anchor & $m l$ & Mooring line \\
$A H V$ & Anchor handling vehicle & $C L V$ & Cable laying vehicle \\
$c a$ & Cables & $a c a$ & Array cables \\
$e c a$ & Export cables & $p p$ & Platform parts \\
$o f s$ & Offshore substation & $o n s$ & Onshore substation \\
$G I S$ & Gas insulated switchgear & $t s$ & Transformer \\
$d t$ & Downtime & $p$ & Port \\
$b l$ & Turbine blade & $t w$ & Turbine tower \\
\hline
\end{tabular}

Table 3: Activities abbreviations

\begin{tabular}{cccc}
\hline Symbol & Name & Symbol & Name \\
\hline$i s$ & Installation on site & $i p$ & Installation at port \\
$t r$ & Transport & $s r$ & Surface rental \\
$l d$ & Load into vessel & $l a$ & Labor \\
$m o$ & Mobilization of vessel & $l f$ & Lifting \\
$i m$ & Machinery internal movements & $s l$ & Soil preparation \\
$f d$ & Foundation & $p a$ & Partial assembling \\
\hline
\end{tabular}

\subsubsection{Wind turbine and floating platform installation costs}

The first installation costs considered are for the floating platforms $I_{f p}$. These costs are estimated assuming specific assembly and transportation procedures for the wind turbine and its platform. The assembly procedure of the wind turbine (tower, rotor, nacelle, and blades) is completed at the port using a crane; then, the full turbine is joined with the floating platform. The joint turbine and platform are loaded into tug vessels to be towed (wet transportation) to the farm site. This transportation method is possible due to the low draft of SSPs [10].

The described installation procedure results in the following costs: port costs $I_{p, f p}$ associated with the storage of turbine and platform components and the use of a port crane to load the assembled turbine into the vessels; transportation costs $I_{t r, f p}$ of using tug vessels, and installation costs $I_{i p, f p}$ associated with the use of the port crane to assemble the turbine and the platform. Therefore, total installation costs for turbines and platforms are [33]:

$$
I_{f p}=I_{p, f p}+I_{t r, f p}+I_{i p, f p}
$$


Port costs $I_{p, f p}$ are calculated using the following equation:

$$
I_{p, f p}=t_{s r, f p} s_{f p} c_{s r}+n_{w t} t_{l d, f p} c_{p c}
$$

where $c_{s r}$ is the cost of port surface rental ( $\left.€ / m^{2} d a y\right), n_{w t}$ is the number of wind turbines, and $c_{p c}$ is the cost of port crane rental $(€ /$ hour $)$. See Appendix A.1 for details on the estimation of these values.

The transportation costs of the platform $I_{t r, f p}$ are defined as:

$$
I_{t r, f p}=n_{t u g, f p} t_{t u g, f p} c_{t u g}+c_{t u g, m o}
$$

with $n_{t u g, f p}$ the number of tugs used per trip, $c_{t u g}$ the daily cost of the tug vessel $(€ / d a y)$, and $c_{\text {tug }, \text { mo }}$ its mobilization cost $(€)$.

The installation cost of the turbine and platform at port is:

$$
\text { Iip, fp }=\frac{t_{i p, f p}}{24} n_{w t} c_{p c}
$$

\subsubsection{Anchoring and mooring installation costs}

The costs of installing the mooring lines and the anchors $I_{a \& m l}$ are calculated assuming that an Anchor Handling Vehicle (AHV) is used for the task and that both the turbine platforms and the substation platforms use the same number of anchors each.

$$
I_{a \& m l}=\left(c_{A H V}+c_{l a, a \& m l}\right) \frac{n_{a}}{R_{A H V}}
$$

where $c_{A H V}$ is the cost of using the $\operatorname{AHV}\left(€_{/} / d a y\right), c_{l a, a \& m l}$ are labor costs $\left(€_{1} / d a y\right)$, and $R_{A H V}$ is the anchor installation rate (per day).

The number of anchors $n_{a}$ is calculated as:

$$
n_{a}=\left(n_{w t}+n_{f p, o f s}\right) n_{m l, f p}
$$

where $n_{f p, o f s}$ is the number of floating platforms for the offshore substation, and $n_{m l, f p}$ is the number of mooring lines per platform.

\subsubsection{Electrical systems installation costs}

The installation costs of electrical systems are divided into installation of cables $I_{c a}$, installation of offshore substation $I_{o f s}$, and installation of onshore substation $I_{\text {ons }}$. The installation costs of cables $I_{c a}$ can be further divided into installation costs of array cables to interconnect the turbines with the offshore substation $I_{a c a}$, export cables that connect the offshore substation with shore $I_{e c a, o f s}$, and onshore export cables $I_{\text {eca,ons }}$ to reach the onshore substation, as shown by Equation 11:

$$
I_{c a}=I_{a c a}+I_{e c a, o f s}+I_{e c a, o n s}
$$

The installation costs for the array cables $I_{a c a}$ are calculated considering the use of specialized vehicles such as Cable Laying Vessels (CLVs) according to Equation 12 [10]: 


$$
I_{a c a}=\frac{c_{C L V, a c a}}{R_{C L V, a c a}} l_{\text {aca }}
$$

where $c_{C L V, a c a}$ is the daily cost of the CLV, and $R_{C L V, a c a}$ its installation rate.

The total length of array cable $l_{a c a}$ depends on the sea depth, the distance between turbines, and the position of the offshore substation relative to the turbines.

The offshore export cable installation costs $I_{\text {eca,ofs }}$ are calculated similarly, but considering that the vessel daily cost $c_{C L V \text {,eca }}$ and installation rate $R_{C L V \text {,eca }}$ vary due to the difference in cables used:

$$
I_{e c a, o f s}=\frac{c_{C L V, e c a}}{R_{C L V, e c a}} l_{e c a, o f s}
$$

with $l_{\text {eca,ofs }}$ the length of offshore export cable $(m)$.

The onshore cable installation costs $I_{\text {eca,ons }}$ are calculated as:

$$
I_{\text {eca,ons }}=c_{\text {eca,ons }} l_{\text {eca,ons }}
$$

where $c_{e c a, \text { ons }}$ is the unitary price of cable installation $(€ / m)$ and $l_{\text {eca,ons }}$ is distance between shore and the onshore substation $(m)$.

The installation costs for the offshore substation $I_{o f s}$ are estimated similarly as in the case of the wind turbines, considering port costs $I_{p, o f s}$, transportation costs $I_{t r, o f s}$, and on-site installation costs $I_{i s, o f s}[33,10]$ :

$$
I_{o f s}=I_{p, o f s}+I_{t r, o f s}+I_{i s, o f s}
$$

The port costs $I_{p, o f s}$ consider the hiring of the port surface to store the transformers and floating platforms $s_{\text {ofs }}$ until they are loaded to be transported, and the rental of the port crane to load the parts into the vessels, as shown by Equation 16 [33]:

$$
I_{p, o f s}=t_{s r, o f s} s_{o f s} c_{s r}+\left(n_{t s}+n_{f p, o f s}\right)\left(t_{l d, t s}+t_{l d, f p}\right) c_{p c}
$$

with $n_{t s}$ the number of transformers. The expressions to estimate these values are presented in Appendix A.2.

The transportation costs for the offshore substation are calculated as:

$$
I_{t r, o f s}=\left(n_{b, o f s} t_{b, o f s} c_{b}\right)+\left(n_{t u g, o f s} t_{t u g, o f s} c_{t u g}\right)+c_{b, m o}+c_{t u g, m o}
$$

where $n_{b, o f s}$ and $n_{\text {tug,ofs }}$ are the number of vessels in the operation.

Finally, the installation costs are estimated as:

$$
I_{i s, o f s}=t_{f c, o f s} c_{f c}+c_{f c, m o}
$$

with $c_{f c}$ and $c_{f c, m o}$ the daily rate and the mobilization cost of the floating crane.

The installation costs for the onshore substation $I_{\text {ons }}$ are estimated using Equation 19 [33]: 


$$
I_{\text {ons }}=I_{s l, o n s}+I_{f d, o n s}+I_{i s, o n s}
$$

with $I_{s l, \text { ons }}$ the costs of preparing the soil, $I_{f d, \text { ons }}$ the cost of the foundation, and $I_{i s, \text { ons }}$ the cost of installation.

\subsubsection{Adaptation costs}

The costs of performing an adaptation depend on the flexibility strategy, as described in section 2.2. For Strategy A, the adaptation costs correspond to the acquisition costs of the new turbines plus the installation costs. In this case, the installation procedure differs from the process followed during the farm construction. The turbines cannot be fully assembled and towed, and instead, they are transported in parts using a barge. Parts of the turbine may be partially assembled at port. The installation at sea is conducted using a floating crane to dismount the old turbines and install the new devices on the existing platforms. The use of floating cranes comes from the assumption that minimizing the adaptation times is the priority. For an alternative objective, a different procedure, such as towing the platforms back to port, could be proposed.

The costs for this installation procedure can be divided in port costs $A_{p}$, transportation costs $A_{t r}$, and installation costs $A_{i s}$, as described by Equation 20:

$$
A=A_{p}+A_{t r}+A_{i s}
$$

Port costs $A_{p}$ consider the rental of storage area at the port and the use of a port crane to load the turbine into the transport vessel:

$$
A_{p}=t_{s r, w t} s_{w t} c_{s r}+n_{w t} t_{l d, w t} c_{p c}
$$

See Appendix A.3 for details on the estimation of these values.

The transportation costs $A_{t r}$ using a barge vessel are defined in Equation 22.

$$
A_{t r}=n_{b, w t} t_{b, w t} c_{b}+c_{m o, b}
$$

The installation costs $A_{i s}$ are divided between the preassembly costs using the port crane and the offshore installation costs using a floating crane, according to Equation 23:

$$
A_{i s}=t_{f c, w t} c_{f c}+c_{f c, m o}+24 t_{p c, p a} c_{p c}
$$

For the case of Strategy B, a slightly different adaptation procedure is followed. This strategy requires the transportation and installation of floating platform expansion elements besides the new turbines. While Equations 20-23 are valid, a few modifications are needed in the number of lifting movements to consider the additional elements that must be loaded, transported, and installed.

Specifically, $n_{l i, w t}$ in Equation A.15 and $n_{l i, i s}$ in Equation A.18 must be increased by the number of platform adaptation parts $n_{p p}$. The number of devices transported per barge vessel $n_{w t, b}$ in Equation 
A.14 also has to be adjusted to account for the additional space on deck required to place the platform parts.

\subsection{Simulation Methodology}

The purpose of the cost model presented in previous sections is to evaluate the impact of flexibility in the economical performance of floating offshore wind farms under uncertain demand, technology prices, and capacity factor. For this purpose, a Monte-Carlo simulation procedure, described in Figure 3, was developed.

\begin{tabular}{|c|c|}
\hline STAGE 1: INPUT & STAGE 2: SIMULATION \\
\hline Define: & Repeat for every simulation episode: \\
\hline General farm properties & For the baseline case calculate: \\
\hline $\begin{array}{l}\text { Distances: } \\
\text { Port - shore } d_{p}\end{array}$ & Initial nominal capacity as $K_{n o m}\left(t_{0}\right)=p r\left(t_{0}\right) n_{w t}$ \\
\hline $\begin{array}{l}\text { Shore - onshore substation } d_{\text {ons }} \\
\text { Farm layout }\end{array}$ & PDD and PM \\
\hline Installation procedure & 1 using equations $5-31$ \\
\hline Quantities: & $\begin{array}{l}\text { For each flexible alternative calculate: } \\
\text { All values as in baseline case }\end{array}$ \\
\hline Offshore and onshore substations $n_{\text {ofs }}, n_{\text {ons }}$ & A using equations $32-42$ \\
\hline Baseline case properties & For $\mathrm{t}=1 \ldots \mathrm{T}$ \\
\hline $\begin{array}{l}\text { Life-cycle period } T_{b c} \\
\text { Initial power rating } \operatorname{pr}\left(t_{0}\right)\end{array}$ & Calculate the effective capacity as $K_{e f}(t)=K_{\text {nom }}(t) c f(t)$ \\
\hline Power rating after rebuilding $\operatorname{pr}\left(T_{b c}\right)$ & $\begin{array}{l}\text { For each nexible alternative: } \\
\text { Verify the adaptation conditions according to policy } \pi_{f}\end{array}$ \\
\hline $\begin{array}{l}\text { Flexibility properties } \\
\text { Implementation strategy }\end{array}$ & Perform an adaptation $K_{n o m}(t+1)>K_{\text {nom }}(t)$ \\
\hline Maximum power rating $p r_{\max }$ & $\begin{array}{l}\text { Calculate cost of ada } \\
\text { the baseline case: }\end{array}$ \\
\hline Policy parameters & Verify if the current life-cycle is complete $t=T_{b}$ \\
\hline Risk profile & Calculate D \\
\hline Size of adaptations & Install new turbine size $\operatorname{pr}\left(T_{b c}\right)$ \\
\hline Cost parameters & Calculate PDD, PM and I for the new farm \\
\hline Unitary prices equations Section 3 & Calculate the energy generated $\mathrm{E}(\mathrm{t})$ \\
\hline Random parameters & Calculate D \\
\hline Energy demand $d(t)$ & Calculate the PV of all costs using equation 2 \\
\hline $\begin{array}{l}\text { Price of turbines } t p(t) \\
\text { Capacity factor } c f(t)\end{array}$ & Calculate the total energy generated using equation 3 \\
\hline Simulation parameters & Calculate the LCOE using equation 4 \\
\hline $\begin{array}{l}\text { Period of analysis } T \\
\text { Number of simulations } n_{\text {sim }}\end{array}$ & \\
\hline \multicolumn{2}{|l|}{ STAGE 3: OUTPUT AND ANALYSIS } \\
\hline \multicolumn{2}{|l|}{ For each batch of $n_{\text {sim }}$ episodes: } \\
\hline \multicolumn{2}{|l|}{ Calculate the average $\mathrm{PV}_{\mathrm{C}}, \mathrm{PV}_{\mathrm{E}}, \mathrm{LCOE}$} \\
\hline \multicolumn{2}{|c|}{ Calculate the standard deviation of these variables } \\
\hline \multicolumn{2}{|l|}{ Repeat Stage 1: INPUT defining new inputs } \\
\hline \multicolumn{2}{|c|}{ Flexibility, policy, cost, and general farm parameters } \\
\hline \multicolumn{2}{|c|}{ Repeat Stage 2: SIMULATION to calculate the key statistics } \\
\hline \multicolumn{2}{|l|}{ of the variables of interest } \\
\hline \multicolumn{2}{|c|}{ Compare the effect that different inputs have on the economic performance } \\
\hline \multicolumn{2}{|l|}{ of the farms } \\
\hline \multicolumn{2}{|l|}{ Histograms } \\
\hline Risk-return diagrams & \\
\hline
\end{tabular}

Figure 3: Stage 1: Input

The procedure consists of 3 stages: Definition of input parameters, simulation, and output analysis. In the first stage, as shown by Figure 3, the parameters that characterize the farm, the costs, the random processes and the policy are defined together with the meta-parameters of the simulation. During the second stage, multiple trajectories of the random processes are simulated, and the discounted life-cycle costs and energy generated are calculated for the different system responses. In the third stage, the average LCOE is estimated for the batch of data from the second stage and 
conclusions are drawn by comparing the results for the flexible and baseline cases. This procedure is repeated for each farm configuration, flexibility strategy, and flexibility policy to be analyzed.

The computational implementation of this methodology can be performed using algorithms of order $O(n)$. The independence between runs encourages the use of parallel computing to reduce processing times. An implementation in $\mathrm{Matlab}^{\oplus} 2017 \mathrm{~b}$ using an Intel $^{\oplus} \mathrm{Core}^{\mathrm{TM}}$ i5-5200 2.20GHz processor takes 15 seconds in average to run one batch of 1000 simulations.

\section{Numerical Example}

The life-cycle cost model presented in section 3 and the simulation procedure presented in section 3.3 are tested using a generic farm. Five cases are considered: flexible Strategy A (i), B (ii), a baseline case (iii), a case with no re-powering (iv), and a re-powering case with no decision flexibility (v). The flexible strategies are described in section 2.2. The baseline case represents a wind farm without flexibility, which is rebuilt once in the middle of the planning horizon. This includes removing all installed components including mooring lines and transmission cables. The case with no re-powering is similar to the baseline case but the farm is never rebuilt. The last case also has over-designed platforms, as in case (i), but the adaptation is always conducted in the middle of the planning horizon. When the the farm is rebuilt or re-powered, the new installed capacity is defined by a required demand/capacity ratio.

The planning horizon is defined as $T=50$ years to allow the comparison of the flexible strategies with two life-cycles of cases (iii) and (v), which are assumed equal to 25 years each [36]. Case (iv) remains unchanged during the entirety of $T$. The farm location is defined at $100 \mathrm{~km}$ from shore (where the port is also located), but a sensitivity analysis of this parameter is considered. Similarly, the initial average sea depth is $100 \mathrm{~m}$ but other depths are addressed in the sensitivity analysis. The farm has 100 units with identical power rating, arranged in a grid pattern of $10 \times 10$ units (see Figure 4). The average distance between units is 7 times the initial turbine diameter. The electrical systems are composed of one substation offshore and one onshore. The offshore substation is located in the center of the grid (Figure 4), while the onshore substation is located $5 \mathrm{~km}$ inland. Wake and electrical losses are assumed constant.

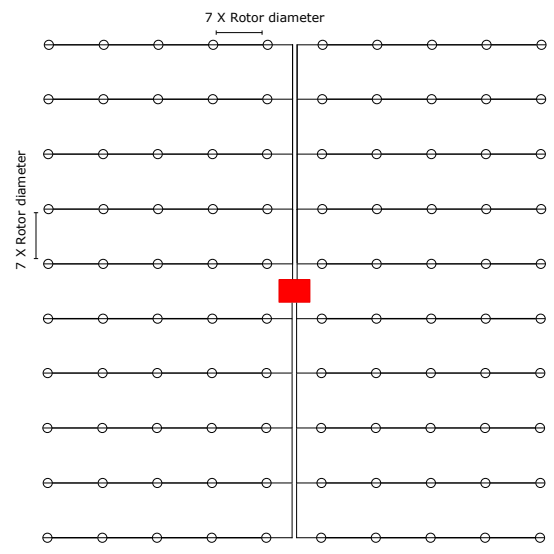

Figure 4: Farm Layout 
Table 4: Costs of planning, development, design and production of turbines and platforms

\begin{tabular}{|c|c|c|c|c|c|}
\hline \multicolumn{6}{|c|}{ Source and values of various unitary prices } \\
\hline \multirow{2}{*}{$P M_{f p}(€ / M W)$} & \multicolumn{4}{|c|}{ Source $[10]$} & Average \\
\hline & \multicolumn{4}{|c|}{1274900} & 1274900 \\
\hline \multirow{2}{*}{$P D D(€ / M W)$} & Source $[1]$ & Source $[2]$ & \multirow{2}{*}{\multicolumn{2}{|c|}{$\begin{array}{c}\text { Source [8] } \\
280600\end{array}$}} & Average \\
\hline & 210000 & 577900 & & & 356167 \\
\hline \multirow{2}{*}{$P M_{w t}(€ / M W)$} & Source[1] & Source[2] & Source $[8]$ & Source $[12]$ & Average \\
\hline & 1300000 & 1197468 & 1581342 & 1305600 & 1348602 \\
\hline
\end{tabular}

Table 5: Mooring and anchoring production costs

\begin{tabular}{llc}
\hline & \multicolumn{1}{c}{ Cost component } & Value \\
\hline \multirow{4}{*}{ Mooring } & Length per turbine & $900 \mathrm{~m}$ \\
& Total length & $90000 \mathrm{~m}$ \\
& Steel density & $177 \mathrm{~kg} / \mathrm{m}$ \\
& Total steel mass & $15930000 \mathrm{~kg}$ \\
& Unitary steel mooring price & $7.92 € / \mathrm{kg}$ \\
\hline \multirow{4}{*}{ Anchoring } & Anchors per turbine & 6 \\
& Anchor weight & $3150 \mathrm{~kg}$ \\
& Total anchor mass & $1980900 \mathrm{~kg}$ \\
& Unitary steel anchoring price & $2 € / \mathrm{kg}$ \\
\hline
\end{tabular}

The cost parameters used to calculate the general costs described in section 3 are presented in the following section. These cost parameters were obtained from multiple sources in the literature.

\subsection{Cost estimation}

The first cost parameters considered are planning, development, and design costs $P D D$; turbine production costs $P M_{w t}$; and floating platform production costs $P M_{f p}$. These costs are generally reported as unitary prices in $€ / M W$ or converted using the rate of exchange of the year of the report and adjusting it by the inflation of 2019. In this example, these costs are estimated as the average unitary price of multiple sources, as shown in Table 4.

In contrast, the mooring and anchoring production costs $P M_{a}, P M_{m l}$ are estimated using a unitary price for the amount of steel required. Therefore, the total costs will depend on the number of anchors per turbine, the length of each mooring line, the density of the steel used, and the unitary price of the steel. The length of each mooring line is defined as 1.5 the average water depth. It is also assumed that 6 mooring lines are used for each wind turbine. Table 5 summarizes these parameters for depths of $100 m$ [10].

The production costs of electrical cables $P M_{a c a}, P M_{e c a}$ are estimated based on a price per unit 
Table 6: Electrical systems costs

\begin{tabular}{lc}
\hline Cost component & Value \\
\hline Unitary price array cables & $279 € / \mathrm{m}$ \\
Unitary price export cables HVDC & $336 € / \mathrm{m}$ \\
Offshore substation & $0.11 \cdot n_{w t} p_{r} \cdot 1 E 6$ \\
Onshore substation & 0.5 Offshore substation cost \\
\hline
\end{tabular}

of length for each type of cable. The length of the inter-array cables is calculated using the layout from Figure 4 assuming that the cables are installed on the seabed. At the midpoint of each row of the grid, the cables are directed towards the offshore substation. The production costs of the offshore and onshore substations $P M_{o f s}, P M_{o n s}$ are estimated using an empirical function of the installed capacity found in the literature [10]. Table 6 presents these costs.

Installation costs for all farm components are calculated using the analytical expressions from sections 3.2.4 - 3.2.3 and the parameters in Table $7[33,10]$.

The costs for the adaptation process are divided between production costs and installation costs. Production costs correspond to the costs of new turbines, offshore and onshore substations, and, in the case of Strategy B, the floating platform expansion elements. Turbine costs are calculated using the prices in Table 4 and the stochastic processes from section 4.2. The costs of the substations are estimated using Table 6.

The operation and maintenance costs $O M$ are generally reported in the literature as a function of both the installed capacity and the farm location. In this study, a linear approximation as a function of the distance to port is considered, for costs ranging between 110000 and $130000 € / \mathrm{MW} /$ year. These values were estimated from recent reports in the literature $[8,35,12]$.

Finally, the decommissioning costs are estimated as a percentage of installation costs plus an additional charge for site cleaning that depends on the farm area. Theses percentages depend on the element, as shown in Table 8 [1].

\subsection{Stochastic parameters}

The simulation process considers the effect from three random processes as described in section 3.3: demand $\delta(t)$, technology (turbine) price $t p(t)$, and capacity factor $c f(t)$. These processes are simulated as time series with shapes and tendencies that follow historical data or predictions reported in the literature. For instance, the demand process is generated according to Equation 24:

$$
\delta(t)=\max \left\{\beta_{1} t+e^{\beta_{2} t} \beta_{3} \sin \left(\beta_{4} t\right) t+\beta_{5}+B(t) t, 0\right\}
$$

where $\beta_{1}$ to $\beta_{5}$ are normally distributed random variables and $B(t)$ is a Wiener process [37]. The values of these variables used in the example are presented in Table 9 . The function $\delta(t)$ allows to simulate a demand tendencies similar to the curves of the prediction models reported in $[38,39,40]$. While 
Table 7: General cost parameters

\begin{tabular}{|c|c|c|c|c|c|}
\hline Parameter & Value & Unit & Parameter & Value & Unit \\
\hline$I_{f d, \text { ons }}$ & 312000 & $€$ & $n_{f p, t u g}, n_{f p, o f s}$ & 1 & platforms \\
\hline$I_{\text {is,ons }}$ & 63500 & $€$ & $n_{f c, w t}$ & 1 & vessels \\
\hline$I_{s l, o n s}$ & 660000 & $€$ & tip, fp & 3 & hours \\
\hline$c_{A H V}$ & 48860 & $€ / d a y$ & $n_{l i, f p}$ & 6 & lifts \\
\hline$c_{b}$ & 35000 & $€ / d a y$ & $n_{l i, o f s}$ & 4 & lifts \\
\hline$c_{C L V, a c a}$ & $91 / 000$ & $€ / d a y$ & $n_{l i, w t}$ Strategy A & 5 & lifts \\
\hline$c_{C L V, e c a}$ & $114 / 000$ & $€ / d a y$ & $n_{l i, w t}$ Strategy B & 8 & lifts \\
\hline$c_{p c}$ & 833.33 & $€ /$ hour & $n_{l i, i s}$ Strategy A & 10 & lifts \\
\hline$c_{f c}$ & 116000 & $€ / d a y$ & $n_{l i, i s}$ Strategy B & 13 & lifts \\
\hline$c_{e c a, o n s}$ & 600 & $€ / m$ & $n_{l i, p a}$ Strategy A\&B & 2 & lifts \\
\hline$c_{l a, a \& m l}$ & 5656 & $€_{/} / d a y$ & $n_{m l, f p}$ & 6 & mooring lines \\
\hline$c_{b, m o}$ & 0 & $€$ & $n_{p p}$ & 3 & parts \\
\hline$c_{f c, m o}$ & 150000 & $€$ & $n_{t s}$ & 3 & transformers \\
\hline$c_{t u g, m o}$ & 0 & $€$ & $n_{t u g, f p}$ & 2 & vessels \\
\hline$c_{s r}$ & 0.02 & $€ / m^{2} d a y$ & $n_{t u g, o f s}$ & 1 & vessels \\
\hline$c_{t u g}$ & 22502 & $€_{1} / d a y$ & $n_{w t}$ & 100 & turbines \\
\hline$\phi_{b l}$ & 0.5 & $\mathrm{~m}$ & $R_{C L V, a c a}$ & 150 & $m / d a y$ \\
\hline$\phi_{t w}$ & 6 & $\mathrm{~m}$ & $R_{C L V, e c a}$ & 200 & $m / d a y$ \\
\hline$d_{p}$ & 100 & $\mathrm{~km}$ & $R_{A H V}$ & 7 & anchors/day \\
\hline$k_{d t}$ & 0.75 & - & $r$ & $3 \%$ & - \\
\hline$l_{b l}$ & 61.5 & $\mathrm{~m}$ & $t_{i m, f c}$ & 8 & hours \\
\hline$l_{\text {eca,ons }}$ & 5000 & $\mathrm{~m}$ & $t_{l i, f p}, t_{l i, o f s}, t_{l i, t s}, t_{l i, w t}$ & 3 & hours \\
\hline$l_{f p}$ & 76 & $\mathrm{~m}$ & $t_{l i, i s}, t_{l i, p a}$ & 3 & hours \\
\hline$l_{G I S}$ & 4 & $\mathrm{~m}$ & $v_{b}$ & 3.6 & $\mathrm{~m} / \mathrm{s}$ \\
\hline$l_{t s}$ & 6.3 & $\mathrm{~m}$ & $v_{f c}$ & 3.14 & $\mathrm{~m} / \mathrm{s}$ \\
\hline$n_{a}$ & 6 & anchors & $v_{t u g}$ & 3.6 & $\mathrm{~m} / \mathrm{s}$ \\
\hline$n_{b, o f s}, n_{b, w t}$ & 1 & vessels & $w_{t s}$ & 5 & $\mathrm{~m}$ \\
\hline$n_{t s, b}$ & 3 & transformers & $w_{G I S}$ & 2.5 & $\mathrm{~m}$ \\
\hline$n_{w t, b}$ Strategy A & 6 & turbines & $n_{w t, b}$ Strategy B & 4 & turbines \\
\hline
\end{tabular}

there is a general linearly increasing tendency, there are local oscillations that simulate mediumterm variability. The addition of the Wiener process allows to model short-term variability, with uncertainty increasing in time. Figure 5a shows instances of the demand trajectories generated by Equation 24.

Similarly, the technology (turbine) price process is generated using Equation 25: 


\begin{tabular}{lc}
\hline Decommissioning item & Percentage of installation costs / Unitary price \\
\hline Turbine and platform & $70 \%$ \\
Electric cables & $10 \%$ \\
Substations & $90 \%$ \\
Mooring lines anchoring & $90 \%$ \\
Site cleaning & $56400 € / \mathrm{km}^{2}[10]$ \\
\hline
\end{tabular}

Table 9: Random demand process parameters

\begin{tabular}{cc}
\hline Parameter & Distribution $\left(\mu, \sigma^{2}\right)$ \\
\hline$\beta_{1}$ & $\mathcal{N}(20,6)$ \\
$\beta_{2}$ & $\mathcal{N}(-0.02,0.006)$ \\
$\beta_{3}$ & $\mathcal{N}(10,3)$ \\
$\beta_{4}$ & $\mathcal{N}(0.5,0.15)$ \\
$\beta_{5}$ & $\mathcal{N}(150,45)$ \\
\hline
\end{tabular}

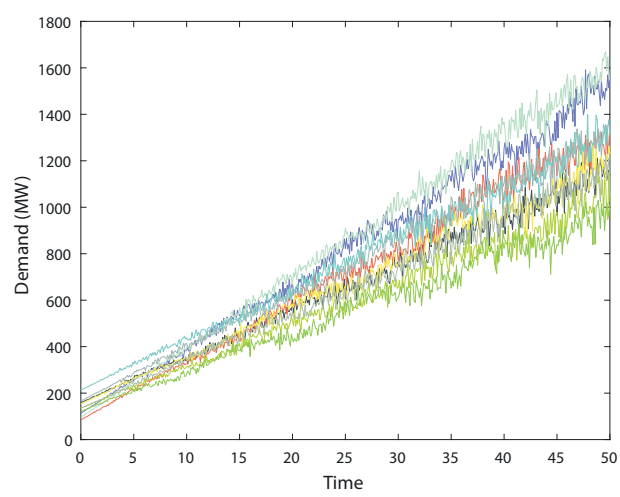

(a) Demand process realizations

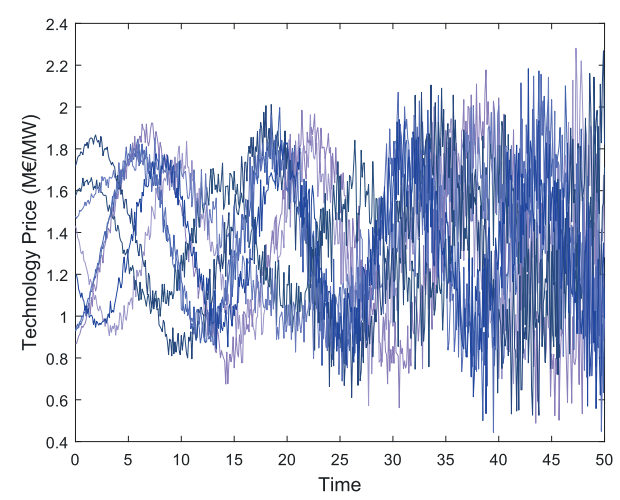

(b) Turbine price process realizations

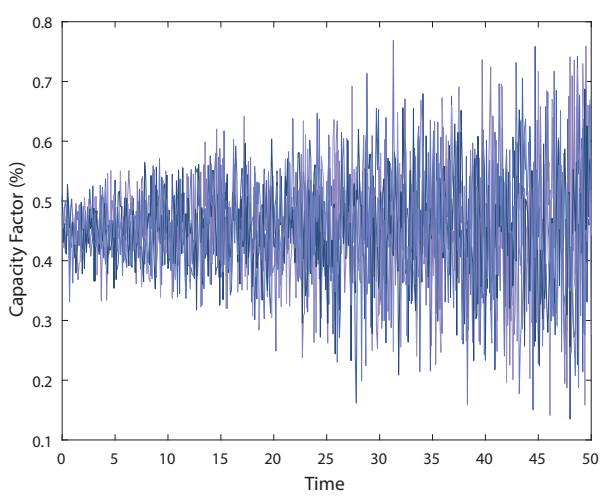

(c) Capacity factor process realizations

Figure 5: Examples of the random processes 


$$
t p(t)=\max \left\{\beta_{1} \sin \left(\beta_{2} t+\beta_{3}\right)+\beta_{4}+B(t) t, 0\right\}
$$

where $\beta_{1}, \beta_{2}$, are normally distributed random variables, $\beta_{3}$ is uniformly distributed, and $\beta_{4}$ is a constant calculated as the average turbine prices reported in Table 4 , and $B(t)$ is a Wiener process. Table 10 presents the parameters of these variables used in the example. The function represents an oscillating trajectory according to the historical data shown in [41]. The oscillating behavior is justified by the variable price of the raw materials, which represent a considerable portion of the total turbine prices. Figure 5b shows instances of the trajectories generated using Equation 25.

Table 10: Random turbine price process parameters

\begin{tabular}{cc}
\hline Parameter & Distribution $\left(\mu, \sigma^{2}\right)$ \\
\hline$\beta_{1}$ & $\mathcal{N}(400000,120000)$ \\
$\beta_{2}$ & $\mathcal{N}(0.4,0.12)$ \\
$\beta_{3}$ & $\mathcal{U}[0,2 \pi]$ \\
$\beta_{4}$ & 1348602 \\
\hline
\end{tabular}

Finally, the capacity factor, which determines the effective capacity of the farm, is simulated as a random process according to the following equation:

$$
c f(t)=\max \left\{\beta_{1} \sin \left(\beta_{2} t\right) t+\beta_{3}+B(t) t, 0\right\}
$$

where $\beta_{1}, \beta_{2}$, are normally distributed random variables, $\beta_{3}$ is an average capacity factor, and $B(t)$ is a Wiener process. Again, the parameters of the variables used in the example are summarized in Table 11. Function $c f(t)$ represent a rapidly oscillating tendency between typical values reported in the literature $[42,43,44]$. The increment in the uncertainty over time is a modeling decision that attempts to capture the difficulty of predicting for such long time periods. In this case, this variability may come from the evolution of environmental conditions, technological evolution of the turbines, and the improvement in the knowledge of the operation. Figure $5 \mathrm{c}$ shows instances of capacity factor trajectories generated by Equation 26.

Table 11: Random capacity factor process parameters

\begin{tabular}{cc}
\hline Parameter & Distribution $\left(\mu, \sigma^{2}\right)$ \\
\hline$\beta_{1}$ & $\mathcal{N}\left(5 \times 10^{-4}, 1.5 \times 10^{-4}\right)$ \\
$\beta_{2}$ & $\mathcal{N}(0.7,0.21)$ \\
$\beta_{3}$ & 0.45 \\
\hline
\end{tabular}

\subsection{Flexibility policy}

The flexibility management policy $\pi_{f}$ discussed in sections 2.1 and 3.3 can be formulated for this example using two functions: First, function $P: \mathbb{R} X \mathbb{R} X \mathbb{R} \rightarrow 0,1$ maps the triplet $(\delta(k), t p(k), c f(k))$ 
at time instant $t=k$ to a value in the interval $[0,1]$. The second function, $Q:[0,1] \rightarrow 0,1$, takes the output of function $P$ and produces a decision: 1 to perform an adaptation and 0 to do nothing. This function requires an input parameter to define this decision threshold, the adaptation trigger AT.

Every time an adaptation decision is triggered, a second parameter, the desired performance after adaptation, PAA, determines the turbine size to be installed based on the ratio demand/effective capacity required after an adaptation is completed. This procedure is repeated until the installed flexibility is depleted. Adaptations outside the flexibility range are not considered in the example.

\subsection{Results of simulation scenarios}

The results presented in this section are the outcome of 1000 simulation episodes generated for a single set of wind farm configurations and management policy parameters. For each episode and set of parameters an installed capacity profile is obtained, as shown in Figure 6. Each episode consists of 501 time steps, which means that the conditions of the decision process are evaluated 10 times per year for the simulation period of 50 years.

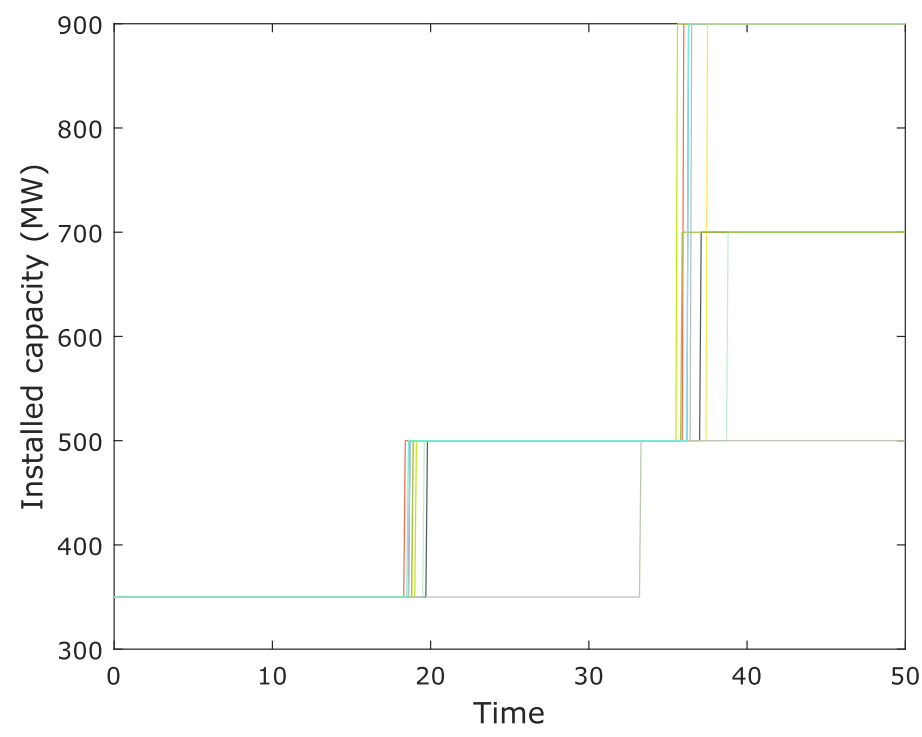

Figure 6: Installed capacity evolution

Each capacity profile is paired with a sequence of investments that occur at different time instants. For instance, all the initial investments ( $P D D, P M$, and $I)$ are assumed as a punctual investment occurring at the first time step. In contrast, the operation and maintenance costs $O M(t)$ are calculated as a sequence of investments uniformly distributed over the simulation period. Adaptation costs $A(t)$ are punctual investments that occur at variable time steps. Instances of the adaptation costs profiles are presented in Figure 7.

The profiles presented in Figures 6 and 7 show that the flexible strategies result in adaptations every $\sim 18$ years, in contrast with the single reconstruction in year 25 for the baseline case. This adaptation frequency and the magnitude of the increments are the result of the policy defined (section 4.3) and the available flexibility. 

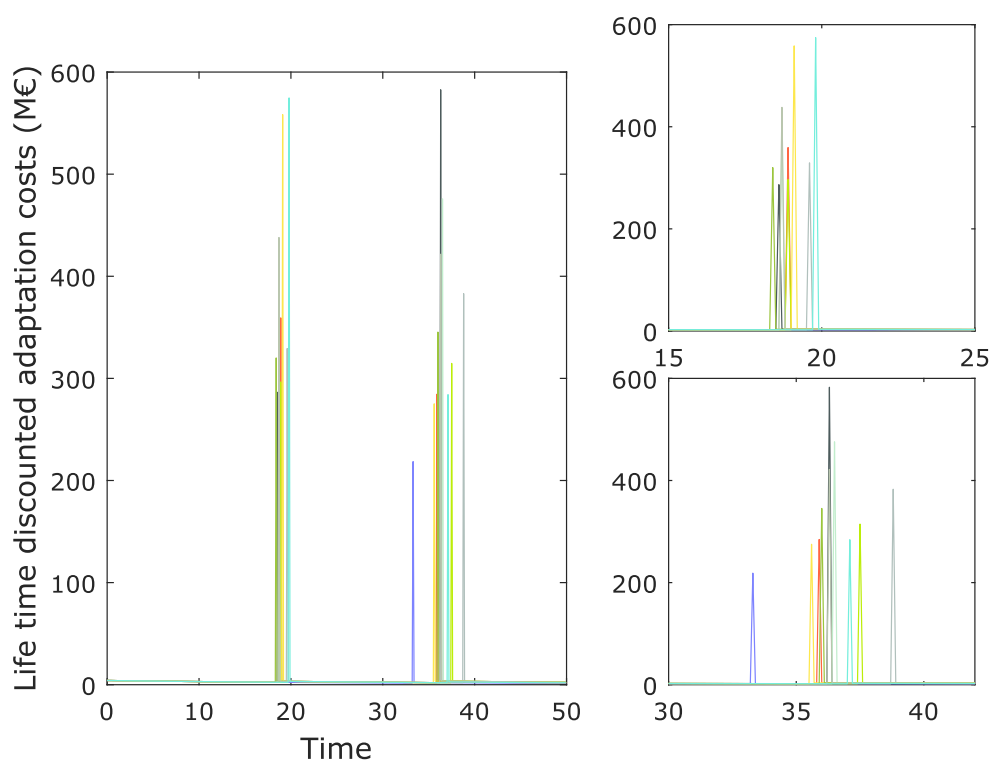

Figure 7: Evolution of discounted adaptation costs

The sensitivity analyses presented in the following sections explore the effect that various parameters related to the implementation of flexibility in floating wind farms have on the LCOE.

\subsubsection{Size of flexibility space}

The first analysis evaluates the impact of the flexibility range on the LCOE. The flexibility range of Equation 1 corresponds to the maximum turbine power rating allowed by the floating platform designs, following either Strategy A or B. The initial power rating is assumed as 8 MW for both flexible strategies and the baseline case. The maximum turbine power rating allowed by flexibility can be [10 121518 20] MW. When a maximum power rating larger than 8MW is selected, the system has access to all intermediate sizes. All sizes are available to rebuild the baseline case at $t=25$ years while case (v) has the same limit as Strategy A.

Figure 8 shows the average LCOE as a function of the flexibility range. The average LCOE values vary between 65 and $95 € / M W h$, which is similar to the values described in the most recent technical reports $[43,44]$. It can be observed that the lowest LCOE is produced by the unchangeable system (case (iv)) followed by Strategy B and the baseline case. This suggests that the cost of replacing the turbines is too large and is not compensated by the additional energy produced. However, case (iv) provides a bound rather than a realistic alternative because it may be too optimistic to assume that a wind farm can operate for 50 years without at least one major replacement.

Figure 8 also shows that both flexible strategies and re-powering case (v) result in lower LCOE compared with the baseline case for maximum power ratings up to $15 \mathrm{MW}$. Beyond that point, implementing flexibility using Strategy A becomes overly expensive, while Strategy B slowly loses its advantage over the baseline case. The difference in slopes between Strategy A and B shows the large impact that expensive flexibility-introduction measures have on the overall economical performance of the farm. Strategy B is competitive because it can take advantage of low turbine prices, as Strategy A, with a lower initial investment. Case (v) follows the same trajectory as Strategy A, but the difference 


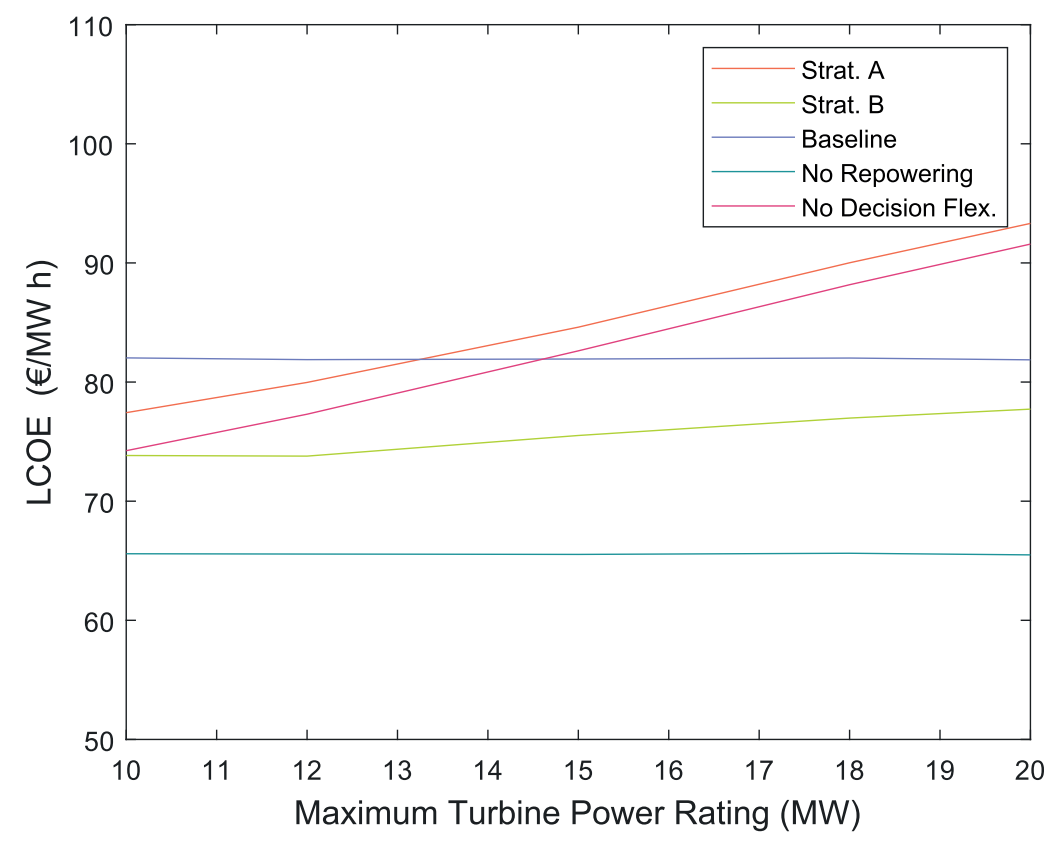

Figure 8: Average LCOE for variable maximum flexible range

in the adaptation timing creates a small gap due to discounting.

Besides the increased cost, the flexible strategies suffer from stagnation in the energy generated, as shown in Figure 9. This figure shows that the flexible strategies are able to generate more energy than all the other options, but the asymptotic behavior observed in both strategies suggests that the external conditions are not sufficient to justify the investments required for the largest flexibility ranges, and this is reflected in the larger LCOE. This highlights the fact that the value offered by flexibility not only depends on the design properties but also on the management policy and the external conditions.

\subsubsection{Policy parameters}

The results from the previous experiment offered a glimpse of the importance of the flexibility management policy. For this analysis, the management policy is defined as described in section 4.3, using two parameters: the adaptation trigger $A T$ and the desired performance after adaptation $P A A$. The first parameter influences the timing of the adaptations while the second parameter affects the magnitude of the change. An $A T$ close to 1 represents an insensitive policy that requires extreme conditions to decide to perform an adaptation. A $P A A$ close to 1 represents a policy that prefers large adaptations, as much as the installed flexibility allows it.

Figure 10 shows the LCOE as a function of the $A T$ for turbines with maximum power rating of $20 \mathrm{MW}$ and initial power rating of $8 \mathrm{MW}$. Increasing $A T$ decreases the LCOE for both flexible strategies, while cases (iii)-(v) are unaffected. Larger $A T$ result in systems that are adapted less frequently by increasing the tolerance to external changes. This results in lower adaptation costs, but also in less energy produced, as can be observed in the energy curve from Figure 11. The sharper fall experienced by both flexible strategies between $A T=0.35$ and $A T=0.4$ suggests that for lower 


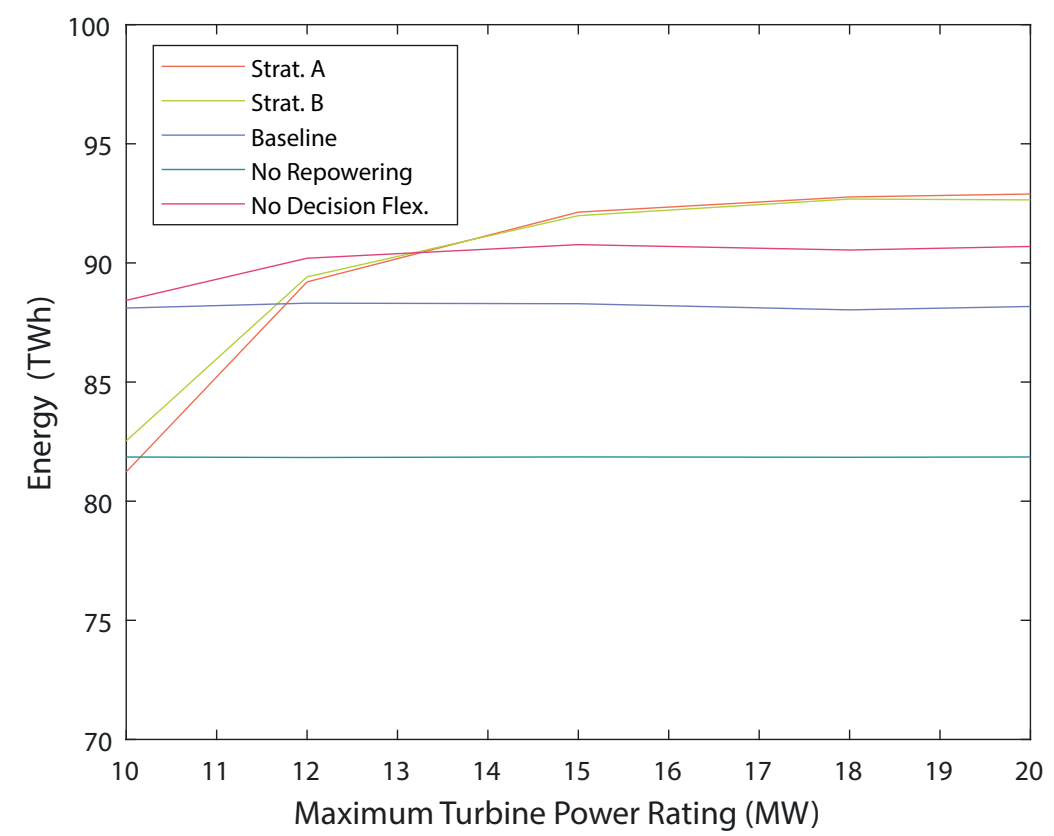

Figure 9: Average discounted energy generated for variable maximum flexible range

values the system is sensitive enough to demand an additional adaptation.

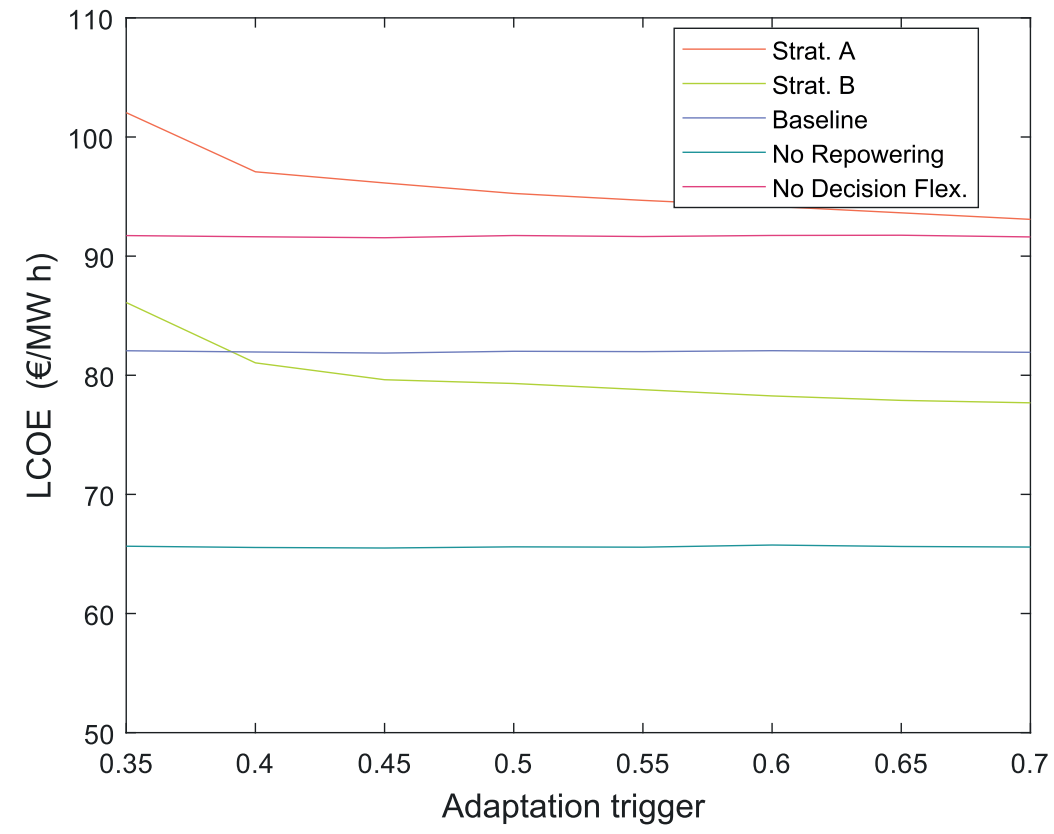

Figure 10: Average LCOE for variable $A T$

The PAA has a smaller impact on the LCOE for the flexible strategies (see Figure 12). This parameter also affects the baseline case and re-powering case (v) because it defines the new size when the system is rebuilt, re-powered, or adapted. Increasing the $P A A$ results in larger and more expensive adaptations, increasing in consequence energy generation as shown by Figure 13. However, the small change in the LCOE suggests that the considerable increment in energy generated barely 


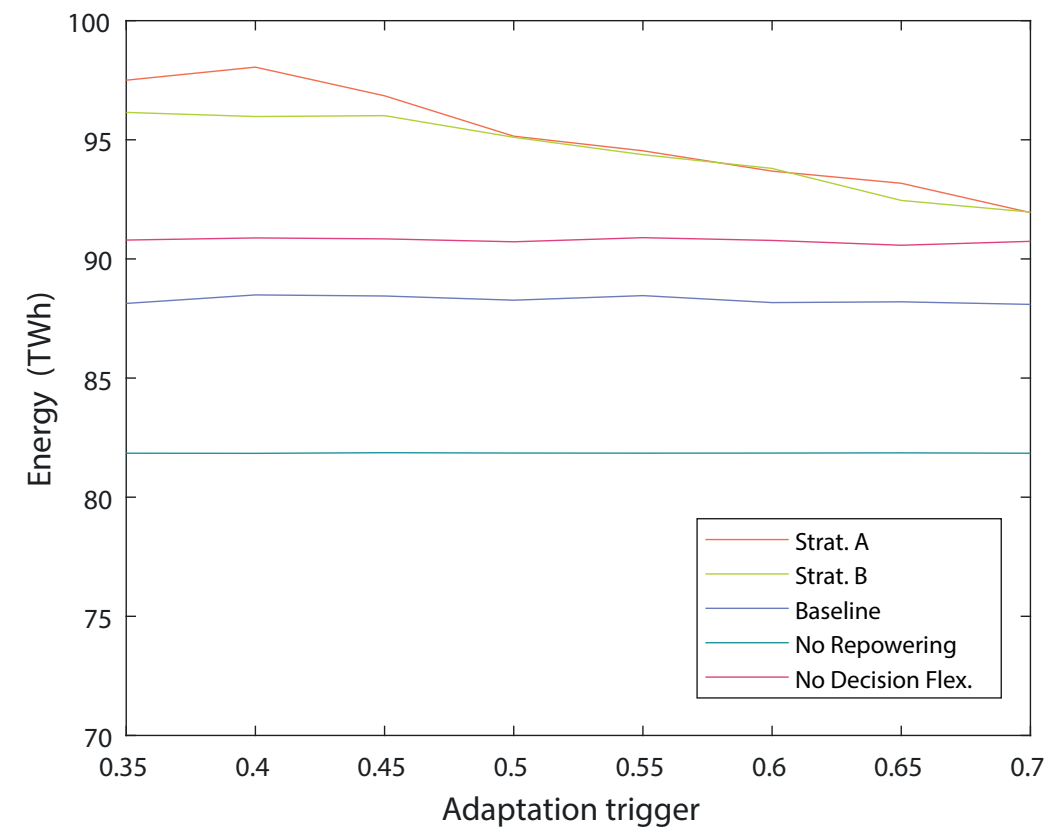

Figure 11: Average discounted energy generated for variable $A T$

offsets the extra costs of adding and using flexibility.

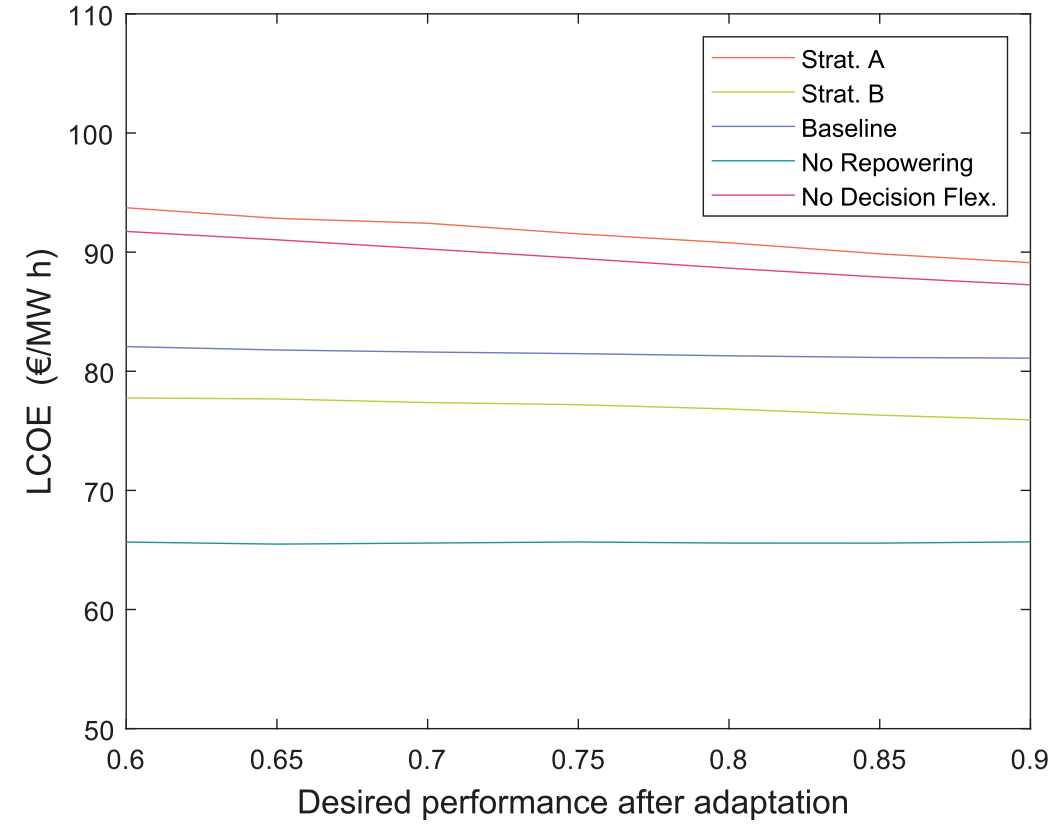

Figure 12: Average LCOE for variable $P A A$

459

460 461

\subsubsection{Initial design}

To explore in more detail the design space, in this section the initial turbine power rating is variable taking values between 6 and $18 \mathrm{MW}$, while the maximum power rating is kept at $20 \mathrm{MW}$.

Figure 14 shows how the average LCOE changes for all cases by increasing the initial design. It is 


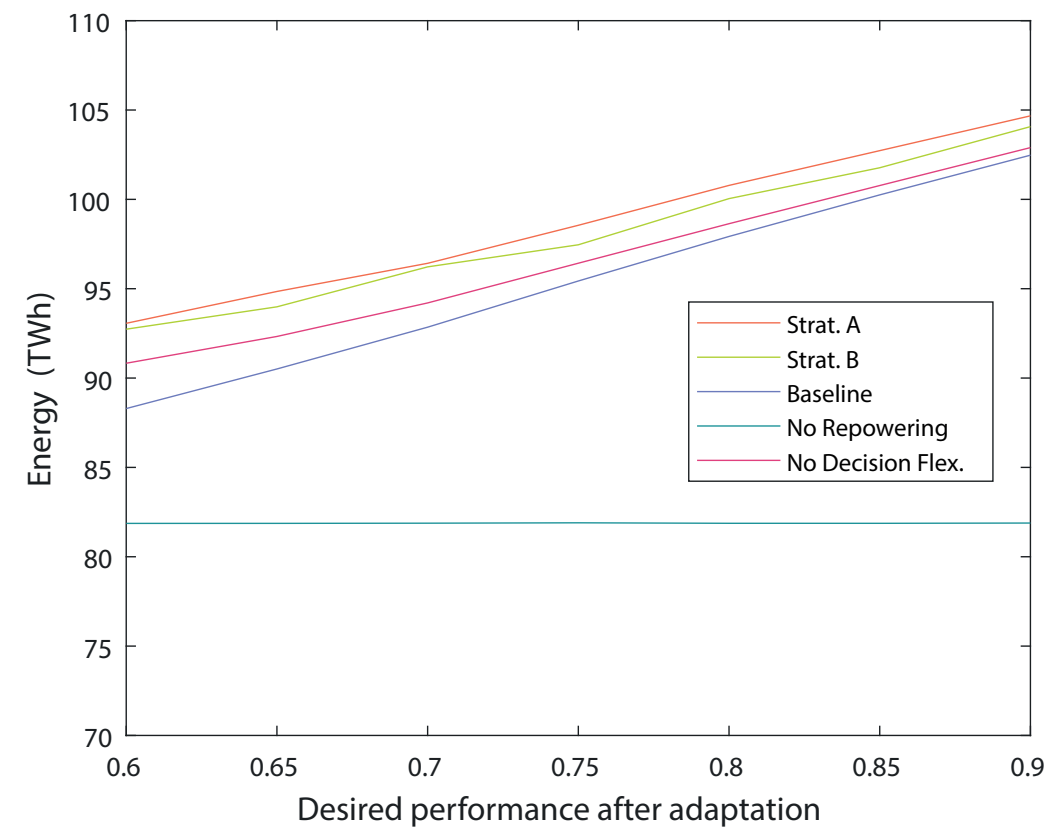

Figure 13: Average discounted energy generated for variable $P A A$

interesting to observe that both flexible strategies converge to the same point, approaching the no re-powering case (iv). In contrast, the baseline case remains almost constant. By increasing the initial design, the flexible strategies may not require adaptations, behaving as case (iv). Cases (iii) and (v) are always modified, but the costs in case (iii) are larger.

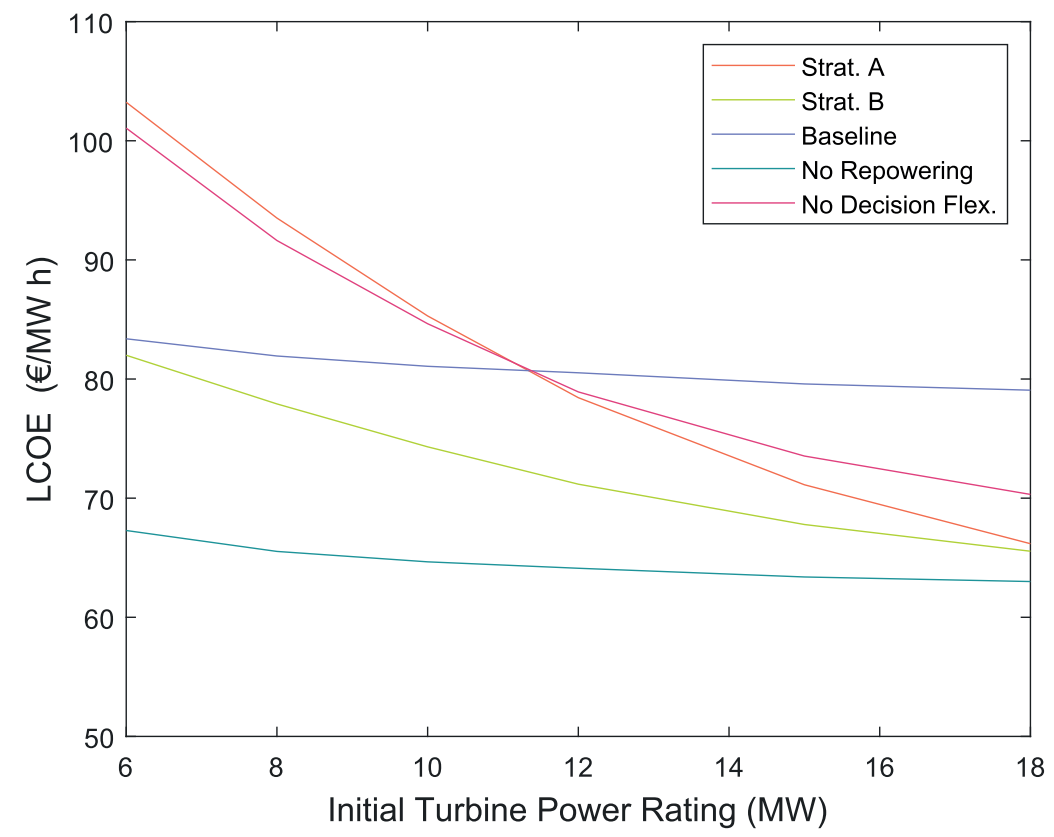

Figure 14: Average LCOE for variable initial turbine rating

These results are in line with previous reports (e.g. [13]) that establish that the most impactful way to reduce the LCOE in offshore wind is to increase the turbine power rating. Nonetheless, this 
policy is not definitive as the capital costs can be prohibitive for many projects, even if there is a considerable reduction in LCOE.

\subsubsection{Distance from port}

In this section, the effect of flexibility on the LCOE is evaluated considering the distance between port and the farm $d_{p}$. It is assumed that the port is located at the nearest shore, and that the water depth increases linearly with the distance from shore. The flexible strategies have a maximum power rating of $20 \mathrm{MW}$.

Previous studies showed the correlation between LCOE, water depth, and distance from shore, due to larger mooring and export cable costs $[1,5]$. Distance also increases installation and adaptation costs, $O M$ costs, and decommissioning costs. Figure 15 shows the LCOE curve for the following set of distances: $[20,30,40,50,100,150,200] \mathrm{km}$. The flexible strategies exhibit an $6 \%$ increment when going from 50 to $100 \mathrm{~km}$, and an increment of $12 \%$ when going from $100 \mathrm{~km}$ to $200 \mathrm{~km}$, which is similar to the $11 \%$ increment by doubling the distance reported in [2].

The baseline case seems to grow faster than Strategy B up to $150 \mathrm{~km}$. While the adaptation costs are slightly affected by the increment in transportation costs, the mooring and electric cables costs have a considerable impact on the costs of rebuilding the farm in the baseline case.

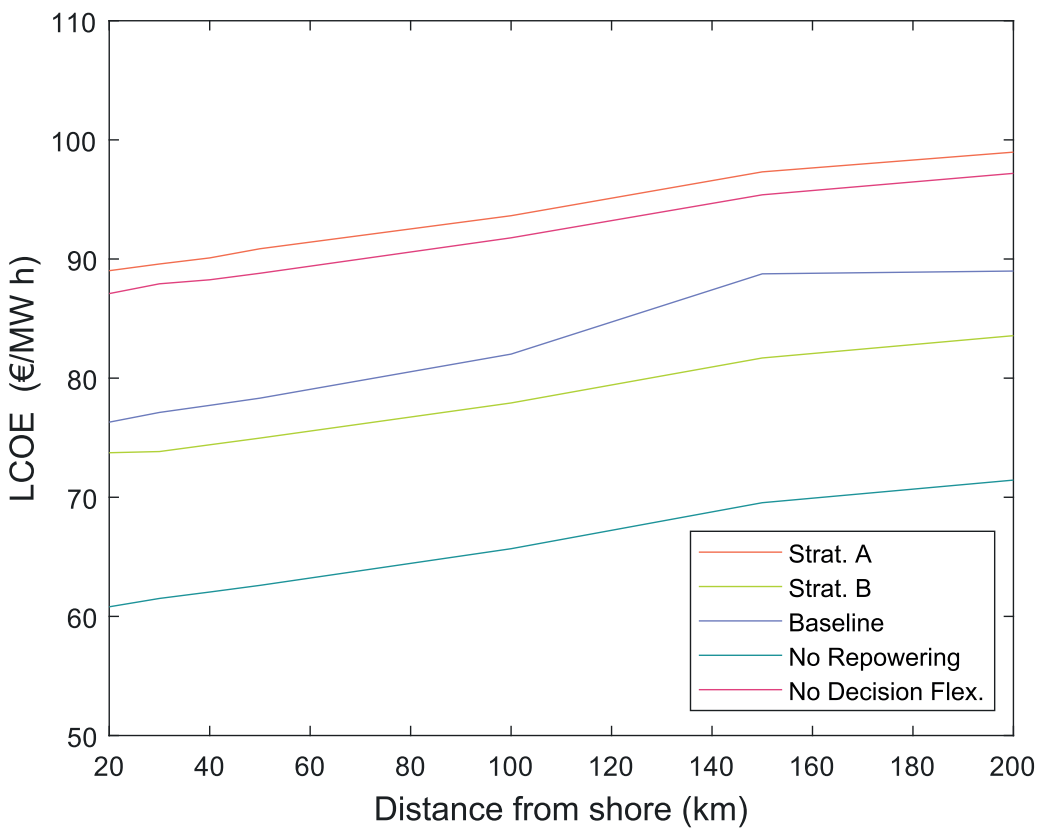

Figure 15: Average LCOE for variable farm location

\subsubsection{Discount rate}

To conclude the parametric analysis, this section compares the effect of the discount rate on the average LCOE. In all the previous analyses a value of $3 \%$ was used considering the long time horizon [45]. Nonetheless, it is of interest to observe how the discount rate affects the economical performance of the alternatives. 
Figure 16 presents the average LCOE of the 5 scenarios for discount rates between $3 \%$ and $10 \%$. Strategy A and the re-powering case exhibit the largest increment in LCOE (2X) due to their relatively large capital costs and the less valuable discounted energy. From 5\%, Strategy B becomes more expensive than the baseline case as the future benefits of flexibility becomes less and less valuable in comparison with the initial investment required to add flexibility.

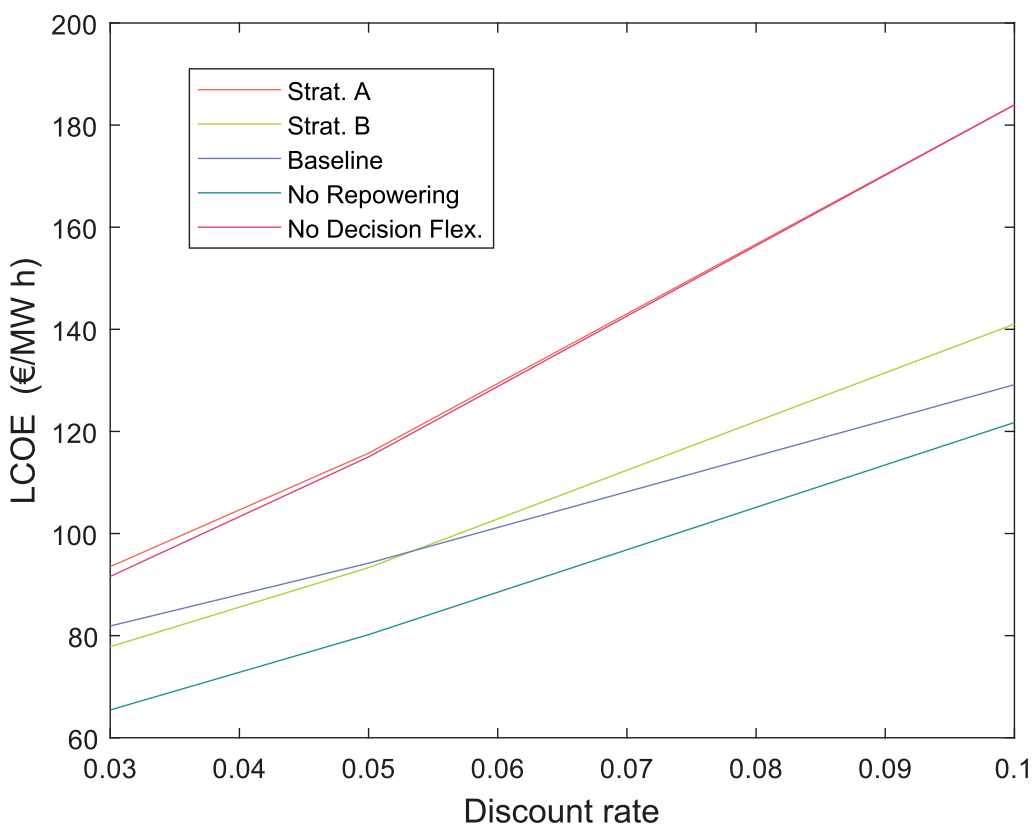

Figure 16: Average LCOE for variable discount rate

\subsubsection{Comparison of flexible strategies and management policies in the Risk-Return space}

The previous comparisons between flexibility ranges and management policies can be summarized in the risk-return space. The risk-return space is used in financial applications to compare portfolios [46]. This tool can be adapted to evaluate the performance of real assets. In this case, the return is replaced by the average LCOE and the risk by the standard deviation of 1000 simulations of the same wind farm configuration and management policy. The result is Figure 17 where each point corresponds to one of the five scenarios with the wind farm located $100 \mathrm{~km}$ from shore/port, with initial turbine power rating between 6 and $18 \mathrm{MW}$, with maximum power rating between $8 \mathrm{MW}$ and $20 \mathrm{MW}$, managed with $A T$ between 0.35 and 0.75 and $P P A$ between 0.5 and 0.9 .

Different marker sizes are used to represent the initial power rating. A clear pattern is detected where the smallest designs produce the worst results in all cases. These points are also associated with large flexibility spaces (larger costs). This effect is stronger for Strategy A and re-powering case (v) due to the larger initial investments. As observed previously, the baseline case and the unchangeable case (iv) exhibit a far less volatile behavior, with a clear layering given by the initial sizes. For Strategy B, even the less desirable combinations are better than those of Strategy A, due to the smaller initial costs. It is interesting to observe that the best configurations of both flexible strategies outperform the best baseline designs. This highlights the importance of finding the optimal 


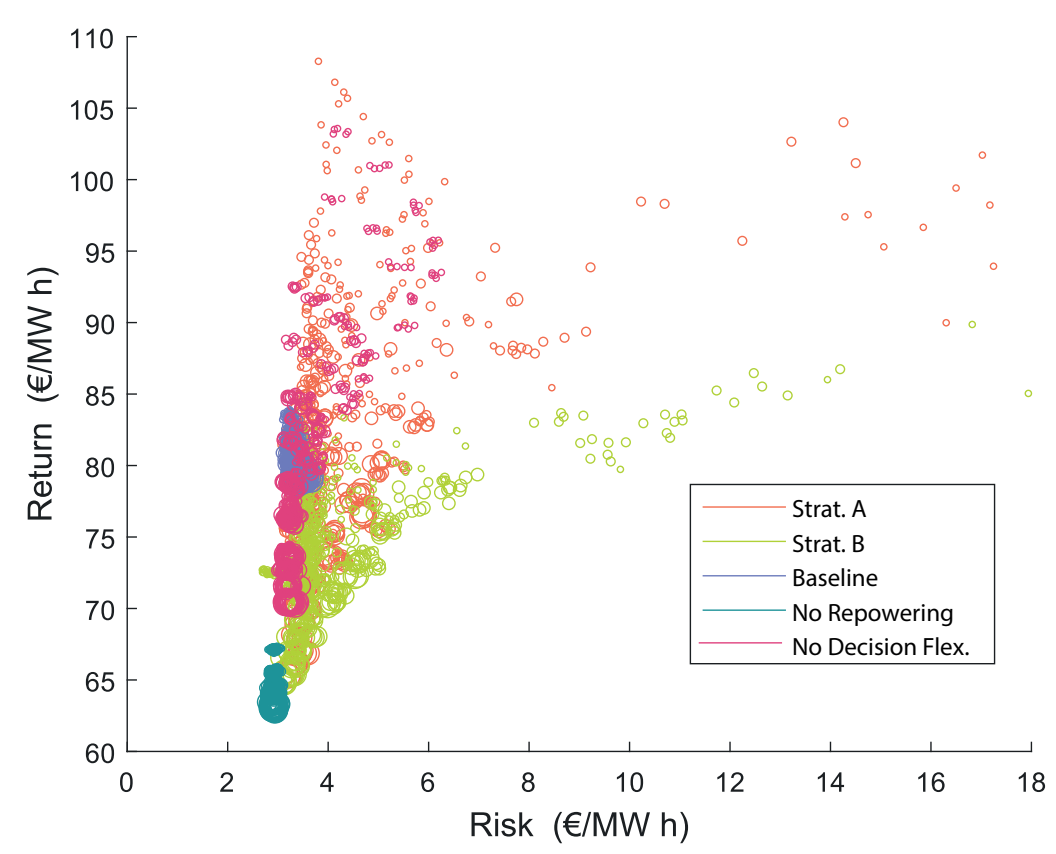

Figure 17: Risk-return space for different farm configurations and management policies

policy for each design. The optimal configurations correspond to large initial power ratings (15 - 18 MW), enough flexibility for one or two adaptations, and large $A T$.

These results are consistent with previous studies that suggest that large power rating turbines have a high impact on reducing energy cost $[14,13,5]$. While this measure increases turbine and platforms capital costs, other costs remain the same or change slightly, and the increment in energy produced is significant. However, the optimal configurations in Figure 17 are not an option right now due to technical limitations, even if large turbines (> $12 \mathrm{MW})$ are under development. It is also not clear how the platform production costs would scale for such massive turbine sizes.

\section{Conclusions}

This paper proposed a methodology for modeling the life cycle performance and estimating the associated costs of flexible solutions for offshore wind turbines. The methodology is a Monte-Carlo based approach to model the response of flexible policies and design strategies to the dynamics of external processes. These processes are modeled as time series that represent uncertain parameters such as demand, capacity factor, and turbine production prices. A life-cycle cost model is used to measure the performance of flexible strategies. Two flexible design strategies were analyzed: overdimensioned platforms and adaptable platforms, both subject to variable flexibility management policies described as functions of the external processes.

In general terms, the results showed that flexibility implemented through the adaptable platform strategy (B) can potentially be a desirable property to have in the wind farm, helping to achieve reductions in LCOE between 12 and $18 \%$ in the best cases, compared with traditionally designed floating wind farms, for operational periods of 50 years. These benefits are partially derived from 
the ability of the flexible alternatives to better react to new contexts, which usually results in more

energy produced at lower investments.

The cost reduction can be partially explained by the weight that production and material costs have on the total costs and, therefore, on the LCOE. By introducing flexibility to the farms, their life-cycle can be prolonged without incurring in all the initial investments required to rebuild at the end of the life-cycle while maintaining the option to deploy changes (new technologies) at a low cost.

However, flexibility not always results in cost reductions, as shown by the results of the overdimensioned platform strategy. This strategy did not show any difference with a re-powering strategy at fixed times. When the investments required to introduce flexibility into the system are too large, the benefits may not be enough to compensate for the additional flexibility costs. Implementing flexibility requires to consider the initial investments, the future adaptation costs, the flexibility management policy, and the expected evolution of the context.

Flexibility and other lifetime extension strategies, such are re-powering, have the potential to be significant cost-reducing measures, under favorable legal frameworks. Additional research to measure not only the effect on lifetime costs but on the sustainability in general of floating offshore farms is required to understand the broad impact of flexibility. Further work is also required to explore the formulation of improved flexibility management policies.

\section{Acknowledgements}

This research received financial support from the Regional Council of 'Pays de la Loire' within the framework of the BUENO 2018-2021 research program (Durable Concrete for Offshore Wind Turbines) and from the Vice-rectory for Research at Universidad de los Andes. 


\section{References}

\section{References}

[1] A. Myhr, C. Bjerkseter, A. Agotnes, T. A. Nygaard, Levelised cost of energy for offshore floating wind turbines in a life cycle perspective, Renewable Energy 66 (2014) 714-728. doi:10.1016/j.renene.2014.01.017.

[2] M. Shafiee, F. Brennan, I. Armada Espinosa, A parametric whole life cost model for offshore wind farms, International Journal of Life Cycle Assessment 21 (2016) 961-975. doi:10.1007/s11367016-1075-z.

[3] P. Morthorst, L. Kitzing, 2 - economics of building and operating offshore wind farms, in: C. Ng, L. Ran (Eds.), Offshore Wind Farms, Woodhead Publishing, 2016, pp. 9 - 27. doi:10.1016/B9780-08-100779-2.00002-7.

[4] R. Green, N. Vasilakos, The economics of offshore wind, Energy Policy 39 (2011) 496 - 502. doi:10.1016/j.enpol.2010.10.011, special Section on Offshore wind power planning, economics and environment.

[5] J. Bosch, I. Staffell, A. D. Hawkes, Global levelised cost of electricity from offshore wind, Energy 189 (2019) 116357. doi:10.1016/j.energy.2019.116357.

[6] B. Möller, L. Hong, R. Lonsing, F. Hvelplund, Evaluation of offshore wind resources by scale of development, Energy 48 (2012) 314 - 322. doi:10.1016/j.energy.2012.01.029, 6th Dubrovnik Conference on Sustainable Development of Energy Water and Environmental Systems, SDEWES 2011.

[7] J. Carroll, A. McDonald, I. Dinwoodie, D. McMillan, M. Revie, I. Lazakis, Availability, operation and maintenance costs of offshore wind turbines with different drive train configurations, Wind Energy 20 (2017) 361-378. doi:10.1002/we.2011.

[8] A. Ioannou, A. Angus, F. Brennan, Stochastic Prediction of Offshore Wind Farm LCOE through an Integrated Cost Model, Energy Procedia 107 (2017) 383-389. doi:10.1016/j.egypro.2016.12.180.

[9] N. Bento, M. Fontes, Emergence of floating offshore wind energy: Technology and industry, Renewable and Sustainable Energy Reviews 99 (2019) 66-82. doi:10.1016/j.rser.2018.09.035.

[10] C. Maienza, A. M. Avossa, F. Ricciardelli, D. Coiro, G. Troise, C. T. Georgakis, A life cycle cost model for flating offhore wind farms, Applied Energy 266 (2020) 114716. doi:10.1016/j.apenergy.2020.114716.

[11] J. Carroll, A. McDonald, D. McMillan, Failure rate, repair time and unscheduled O\&M cost analysis of offshore wind turbines, Wind Energy 19 (2016) 1107-1119. doi:10.1002/we.1887. 
[12] F. Judge, F. D. McAuliffe, I. B. Sperstad, R. Chester, B. Flannery, K. Lynch, J. Murphy, A lifecycle financial analysis model for offshore wind farms, Renewable and Sustainable Energy Reviews 103 (2019) 370-383. doi:10.1016/j.rser.2018.12.045.

[13] The Crown State, Offshore wind cost reduction, pathways study, The Crown State, 2012.

[14] M. I. Blanco, The economics of wind energy, Renewable and Sustainable Energy Reviews 13 (2009) 1372 - 1382. doi:10.1016/j.rser.2008.09.004.

[15] R. De Neufville, S. Scholtes, Flexibility in Engineering Design, Engineering systems, 1st ed., MIT Press, 2011.

[16] M. Mortazavi-Naeini, G. Kuczera, L. Cui, Application of multiobjective optimization to scheduling capacity expansion of urban water resource systems, Water Resources Research (2014) 46244642. doi:10.1002/2013WR014569.

[17] C. C. Fraga, J. Medellín-Azuara, G. F. Marques, Planning for infrastructure capacity expansion of urban water supply portfolios with an integrated simulation-optimization approach, Sustainable Cities and Society 29 (2017) 247-256. doi:10.1016/j.scs.2016.11.003.

[18] T. Erfani, K. Pachos, J. J. Harou, Real-Options Water Supply Planning: Multistage Scenario Trees for Adaptive and Flexible Capacity Expansion Under Probabilistic Climate Change Uncertainty, Water Resources Research 54 (2018) 5069-5087. doi:10.1029/2017WR021803.

[19] M. V. Chester, B. Allenby, Toward adaptive infrastructure: flexibility and agility in a non-stationarity age, Sustainable and Resilient Infrastructure 4 (2019) 173-191. doi:10.1080/23789689.2017.1416846.

[20] A. M. Ross, D. H. Rhodes, D. E. Hastings, Defining Changeability : Reconciling Flexibility , Adaptability, Scalability , Modifiability, and Robustness for Maintaining System Lifecycle Value, Systems Engineering 11 (2008) 246-262. doi:10.1002/sys.

[21] J. H. Saleh, G. Mark, N. C. Jordan, Flexibility : a multi-disciplinary literature review and a research, Journal of Engineering Design 20 (2009) 307-323. doi:10.1080/09544820701870813.

[22] O. Špačková, D. Straub, Long-term adaption decisions via fully and partially observable Markov decision processes, Sustain Resilient Infrastruct 2 (2017) 37-58. doi:10.1080/23789689.2017.1278995.

[23] M. Sánchez-Silva, Managing infrastructure systems through changeability, Journal of Infrastructure Systems 25 (2019) 04018040. doi:10.1061/(ASCE)IS.1943-555X.0000467.

[24] S. Torres-Rincón, D. F. Villarraga, M. Sánchez-Silva, Conceptual and Numerical Analysis of Flexibility in Infrastructure Systems, Journal of Infrastructure Systems 26 (2020) 04020012. doi:10.1061/(ASCE)IS.1943-555X.0000546. 
[25] M.-A. Cardin, M. Ranjbar-Bourani, R. De Neufville, Improving the Lifecycle Performance of Engineering Projects with Flexible Strategies: Example of On-Shore LNG Production Design, Systems Engineering 18 (2015) 253-268. doi:10.1002/sys.21301.

[26] M. Fitzgerald, Managing Uncertainty in Systems with a Valuation Approach for Strategic Changeability, Master's Thesis. Massachusetts Institute of Technology, 2012.

[27] M. A. Cardin, S. Zhang, W. J. Nuttall, Strategic real option and flexibility analysis for nuclear power plants considering uncertainty in electricity demand and public acceptance, Energy Economics 64 (2017) 226-237. doi:10.1016/j.eneco.2017.03.023.

[28] W. B. Powell, Approximate Dynamic Programming: Solving the Curses of Dimensionality, 2nd ed., Wiley, 2011.

[29] S. Zhao, W. B. Haskell, M. A. Cardin, Decision rule-based method for flexible multi-facility capacity expansion problem, IISE Transactions 50 (2018) 553-569. doi:10.1080/24725854.2018.1426135.

[30] M. J. Kochenderfer, C. Amato, G. Chowdhary, J. P. How, H. J. D. Reynolds, J. R. Thornton, P. A. Torres-Carrasquillo, N. K. Üre, J. Vian, Decision Making Under Uncertainty: Theory and Application, 1st ed., The MIT Press, 2015.

[31] H. Díaz, J. M. Rodrigues, C. Guedes Soares, Preliminary cost assessment of an offshore floating wind farm installation on the galician coast, in: C. Guedes Soares (Ed.), Progress in Renewable Energies Offshore. Proceedings of the 2nd International Conference on Renewable Energies Offshore, Taylor \& Francis, 2016, pp. 843-850.

[32] L. Castro-Santos, V. Diaz-Casas, Life-cycle cost analysis of floating offshore wind farms, Renewable Energy 66 (2014) 41-48. doi:10.1016/j.renene.2013.12.002.

[33] L. Castro-Santos, A. Filgueira-Vizoso, I. Lamas-Galdo, L. Carral-Couce, Methodology to calculate the installation costs of offshore wind farms located in deep waters, Journal of Cleaner Production 170 (2018) 1124 - 1135. doi:10.1016/j.jclepro.2017.09.219.

[34] L. Castro-Santos, E. Martins, C. Guedes Soares, Methodology to Calculate the Costs of a Floating Offshore Renewable Energy Farm, Energies 9 (2016) 324. doi:10.3390/en9050324.

[35] C. Mone, M. Hand, M. Bolinger, J. Rand, D. Heimiller, J. Ho, 2015 cost of wind energy review, National Renewable Energy Laboratory (NREL), 2017. doi:10.2172/1351062.

[36] E. Topham, D. McMillan, S. Bradley, E. Hart, Recycling offhore wind farms at decommissioning stage, Energy Policy 129 (2019) 698-709. doi:10.1016/j.enpol.2019.01.072.

[37] M. Sánchez-Silva, G.-A. Klutke, Relibility and Life-Cycle Analysis of Deteriorating Systems, 1st ed., Springer International, 2016. 
[38] M. Duran Toksarı, Ant colony optimization approach to estimate energy demand of turkey, Energy Policy 35 (2007) 3984 - 3990. doi:10.1016/j.enpol.2007.01.028.

[39] C. García-Ascanio, C. Maté, Electric power demand forecasting using interval time series: A comparison between var and imlp, Energy Policy 38 (2010) 715 - 725. doi:10.1016/j.enpol.2009.10.007.

[40] N. Alabbas, J. Nyangon, Weather-based long-term electricity demand forecasting model for saudi arabia: A hybrid approach using end-use and econometric methods for comprehensive demand analysis, 2016.

[41] R. H. Wiser, M. Bolinger, 2011 wind technologies market report, National Renewable Energy Laboratory (NREL), 2012.

[42] The Crown State, Offshore wind operational report, The Crown State, 2019.

[43] T. Stehly, P. Beiter, P. Duffy, 2019 cost of wind energy review, National Renewable Energy Laboratory (NREL), 2020.

[44] W. Musial, P. Beiter, P. Spitsen, J. Nunemaker, V. Gevorgian, A. Cooperman, R. Hammond, M. Shields, 2019 offshore wind technology data update, National Renewable Energy Laboratory (NREL), 2020.

[45] E. Bastidas-Arteaga, M. G. Stewart, Economic assessment of climate adaptation strategies for existing reinforced concrete structures subjected to chloride-induced corrosion, Structure and Infrastructure Engineering 12 (2016) 432 - 449. doi:10.1080/15732479.2015.1020499.

[46] F. K. Crundwell, Finance for Engineers: Evaluation and Funding of Capital Projects, 1 ed., Springer Verlag, 2008.

\section{Appendix A. Detailed Equations}

\section{Appendix A.1. Installation of turbines and platforms}

The rental time of storage surface for the floating platforms $t_{s r, f p}$ (days) is calculated as:

$$
t_{s r, f p}=\frac{t_{i p, f p} n_{w t}}{24}+t_{t u g, f p}
$$

The assembling time of platforms at port $t_{i p, f p}$ is calculated as:

$$
t_{i p, f p}=n_{l i, f p} t_{l i, f p}
$$

where $n_{l i, f p}$ is the number of lifting movements to assemble turbine and platform, and $t_{l i, f p}$ is the time required for one lifting movement (hours).

The usage time of the tug vessels $t_{t u g, f p}$ is calculated (days) as:

$$
t_{t u g, f p}=\left(n_{f p, t u g} t_{l d, f p}+\frac{2}{3600} \frac{d_{p}}{v_{t u g}}\right) \frac{n_{w t}}{n_{f p, t u g}} \frac{1}{24 k_{d t}}
$$


with $n_{f p, t u g}$ the number of platforms towed per trip, $v_{t u g}$ the speed of the tug vessel $(m / s), d_{p}$ the distance between port and farm $(m)$, and $k_{d t}$ a downtime coefficient.

The rented surface at port $s_{f p}$ is defined as:

$$
s_{f p}=n_{w t} l_{f p} \sqrt{l_{f p}^{2}-\left(\frac{l_{f p}}{2}\right)^{2}}
$$

where $l_{f p}$ is the platform length.

\section{Appendix A.2. Installation of electrical systems}

The rental time of port surface $t_{s r, o f s}($ days) is calculated assuming that: i) a barge is used to transport the transformers to the offshore site, ii) a tug is used to tow the floating platform, and iii) a floating crane is used to assemble the substation in situ [10]. The parameter $t_{s r, o f s}$ is defined as the sum [33]:

$$
t_{s r, o f s}=t_{b, o f s}+t_{t u g, o f s}+t_{f c, o f s}
$$

The barge usage time $t_{b, s o}($ days) is calculated as:

$$
t_{b, o f s}=\left(\frac{2}{3600} \frac{d_{p}}{v_{b}}+n_{t s, b} t_{l d, t s}\right) \frac{n_{t s}}{24 k_{d t}}
$$

with $v_{b}$ the speed of the barge vessel $(\mathrm{m} / \mathrm{s}), n_{t s, b}$ the number of transformers transported in one barge, and $n_{\text {ofs }}$ the number of offshore substations.

The time to load one transformer $t_{l d, t s}$ is calculated as:

$$
t_{l d, t s}=n_{l i, t s} t_{l i, t s}
$$

where $n_{l i, t s}$ is the number of liftings to load one transformer and $t_{l i, t s}$ the time required (hours).

The tug usage time $t_{t u g, o f s}$ is calculated as:

$$
t_{t u g, o f s}=\left(\frac{2}{3600} \frac{d_{p}}{v_{t u g}}+n_{f p, o f s} t_{l d, f p}\right) \frac{n_{o f s}}{24 k_{d t}}
$$

The time to load the substation platforms $t_{l d, f p}$ is calculated as:

$$
t_{l d, f p}=n_{l i, f p} t_{l i, f p}
$$

The floating crane usage time $t_{f c, o f s}$ is calculated as:

$$
t_{f c, o f s}=\left(\frac{2}{3600} \frac{d_{p}}{v_{f c}}+t_{i s, o f s}+t_{i m, f c}\right) \frac{n_{o f s}}{24 k_{d t}}
$$

with $v_{f c}$ the speed of the floating crane $(\mathrm{m} / \mathrm{s})$ and $t_{i s, o f s}$ the time between internal movement of the floating crane (hours).

The installation time of the offshore substation $t_{i s, o f s}$ is calculated as:

$$
t_{i s, o f s}=n_{l i, o f s} t_{l i, o f s}
$$


The port surface $s_{\text {ofs }}$ is defined as [33]:

$$
s_{o f s}=n_{t s}\left(l_{t s} w_{t s}+l_{G I S} w_{G I S}\right)(1+1.5)
$$

The on-site installation time of the turbines $t_{i s, w t}$ is calculated according to Equation A.18:

$$
t_{i s, w t}=n_{l i, i s} t_{l i, i s}
$$

${ }_{711}$ The rented surface at port $s_{w t}$ is based on the space required to store the turbines and is calculated 712 as [33]:

$$
s_{w t}=3 n_{w t} l_{b l} \phi_{b l}+3 n_{w t} \pi\left(\frac{\phi_{t w}}{2}\right)^{2}
$$

${ }_{713}$ where $l_{b l}$ is the length of the blades, and $\phi_{b l}, \phi_{t w}$ are the diameters of the blades and the tower. 